A Norm-Independent Technique for Assessing

Physical Ability of the Severely Disabled

by

Deanna J. Clay

Thesis submitted to the Faculty of the

Virginia Polytechnic Institute and State University

in partial fulfillment of the requirements for the degree of

Master of Science

in

Industrial Engineering and Operations Research

APPROVED:

Prof. Paul T. Kemmerling, Chairman

Dr. K.H.E. Kroemer

Dr. Robert D. Dryden

Dr. Susan B. Asselin

September 18, 1987

Blacksburg, Virginia 


\section{A Norm-Independent Technique for Assessing Physical Ability of the Severely Disabled}

by

Deanna J. Clay

Prof. Paul T. Kemmerling, Chairman

Industrial Engineering and Operations Research

(ABSTRACT)

The need for a new technique for assessing the physical ability of severely disabled persons became evident through experience with some of the existing techniques. A technique was developed which attempts to overcome some of the difficulties found with the other techniques.

One of the distinguishing properties of this technique is that it is normindependent. This means it does not reference a normal scale of performance, thus it does not compare the performance of a disabled person to a standard established by able-bodied persons. Additional properties possessed by this technique also set it apart from the others: it is limited to a test of manipulation ability; it generates a profile of ability; it incurs only a minimal expense ; it requires only a minimal amount of time; and there is no required training course for the administrator. 


\section{Acknowledgements}

I would like to thank my chairman and committee members for their guidance and advice during this project. John Ward also provided creative and valuable input. Special thanks go to Marc Hunter and Greg Taylor for their photography and graphics skills respectively.

As always, my parents were a limitless source of inspiration, support, and patience. 


\section{Table of Contents}

INTRODUCTION $\ldots \ldots \ldots \ldots \ldots \ldots \ldots \ldots \ldots \ldots \ldots \ldots \ldots \ldots \ldots \ldots \ldots$

History of Rehabilitation and Assessment $\ldots \ldots \ldots \ldots \ldots \ldots \ldots \ldots$

Applications of Physical Ability Assessment $\ldots \ldots \ldots \ldots \ldots \ldots \ldots \ldots \ldots \ldots$

Review of Contemporary Assessment Techniques $\ldots \ldots \ldots \ldots \ldots \ldots \ldots$

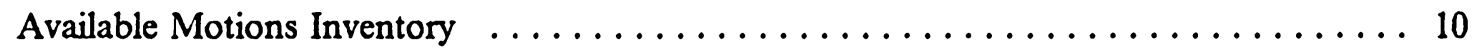

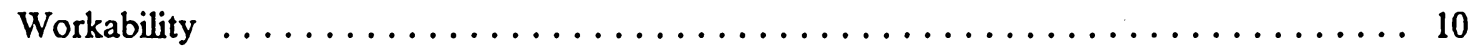

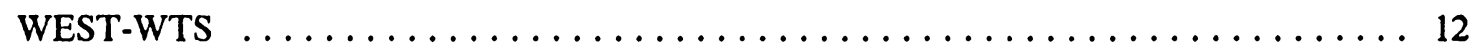

Sensor Pegboard Test Method $\ldots \ldots \ldots \ldots \ldots \ldots \ldots \ldots \ldots \ldots \ldots \ldots \ldots$

Vocational Assessment Techniques $\ldots \ldots \ldots \ldots \ldots \ldots \ldots \ldots \ldots \ldots \ldots \ldots$

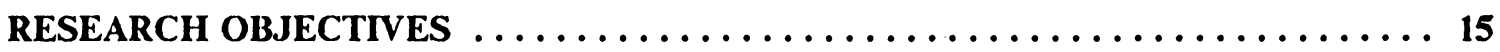

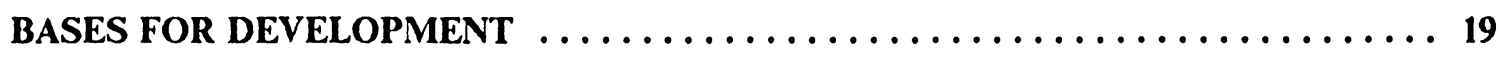

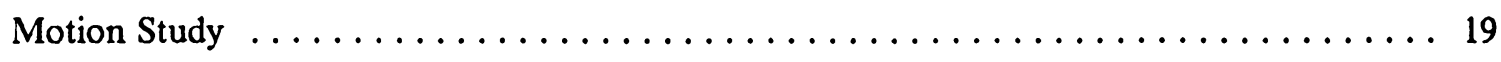

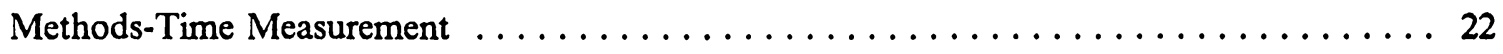

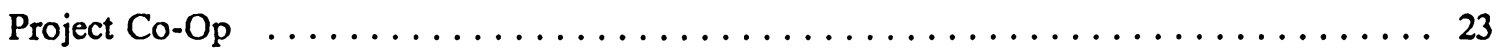


DISCUSSION

REFERENCES

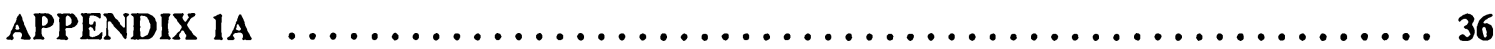

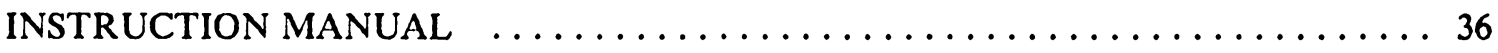

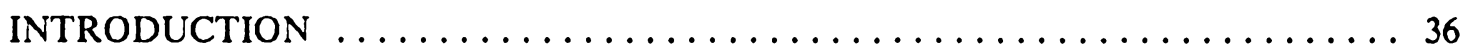

Frequently Used Terms $\ldots \ldots \ldots \ldots \ldots \ldots \ldots \ldots \ldots \ldots \ldots \ldots$

THE PRE-ASSESSMENT PHASE $\ldots \ldots \ldots \ldots \ldots \ldots \ldots \ldots \ldots \ldots$

Administration of the Pre-Assessment Questionnaires $\ldots \ldots \ldots \ldots \ldots$

Interpreting the Pre-Assessment Information Questionnaires (Part I) . . . . . 40

Interpreting the Pre-Assessment Information Questionnaire (Part II) . . . . 43

THE ASSESSMENT PHASE $\ldots \ldots \ldots \ldots \ldots \ldots \ldots \ldots \ldots \ldots \ldots$

General Guidelines on Assessment $\ldots \ldots \ldots \ldots \ldots \ldots \ldots \ldots$

Assessment Bases and Procedures $\ldots \ldots \ldots \ldots \ldots \ldots$

THE POST-ASSESSMENT PHASE $\ldots \ldots \ldots \ldots \ldots \ldots \ldots \ldots \ldots$

Interpreting and Applying the Results $\ldots \ldots \ldots \ldots \ldots \ldots$

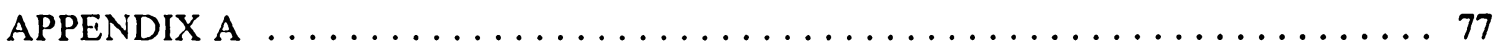

PRE-ASSESSMENT INFORMATION QUESTIONNAIRES . . . . . . . . . 77

Pre-Assessment Information (Part I) $\ldots \ldots \ldots \ldots \ldots \ldots \ldots \ldots$

Pre-Assessment Information (Part II) $\ldots \ldots \ldots \ldots \ldots \ldots \ldots \ldots \ldots$

APPENDIX B $\ldots \ldots \ldots \ldots \ldots \ldots \ldots \ldots \ldots \ldots \ldots \ldots \ldots \ldots \ldots \ldots \ldots \ldots \ldots$

EVALUATION FORMS $\ldots \ldots \ldots \ldots \ldots \ldots \ldots \ldots \ldots \ldots \ldots \ldots \ldots$ 
Reach Evaluation $\ldots \ldots \ldots \ldots \ldots \ldots \ldots \ldots \ldots \ldots \ldots \ldots$

Grasp and Release Evaluation $\ldots \ldots \ldots \ldots \ldots \ldots . \ldots . \ldots . \ldots 8$

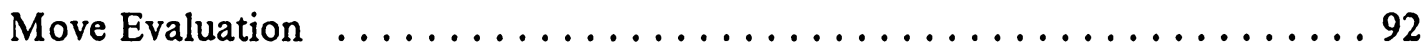

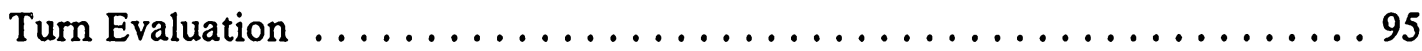

Position Evaluation $\ldots \ldots \ldots \ldots \ldots \ldots \ldots \ldots \ldots \ldots \ldots \ldots$

Engage/Disengage Evaluation $\ldots \ldots \ldots \ldots \ldots \ldots \ldots \ldots \ldots \ldots$

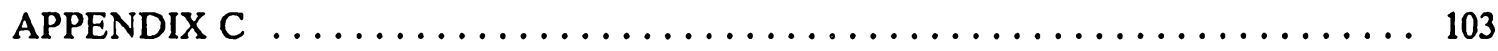

REQUIRED MATERIALS $\ldots \ldots \ldots \ldots \ldots \ldots \ldots \ldots \ldots \ldots \ldots \ldots \ldots$ 


\section{List of Illustrations}

Figure 1. An effective approach to employment $\ldots \ldots \ldots \ldots \ldots \ldots \ldots$

Figure 2. A strategy for employment $\ldots \ldots \ldots \ldots \ldots \ldots \ldots \ldots \ldots \ldots$

Figure 3. Process for job accommodation (Alexander, 1986) . . . . . . . . . 9

Figure 4. Test panel positions in the AMI framework $\ldots \ldots \ldots \ldots \ldots \ldots 11$

Figure 5. Areas covered by reach and move (Karger and Bayha, 1987). . . . . 28

Figure 6. Placement of spools for a case $1 \mathrm{Cl}$ Grasp. ............ 58

Figure 7. Placement of pencils for a case 1 C2 Grasp. ............ 59

Figure 8. Placement of toothpicks for a case $1 \mathrm{C} 3$ grasp. $\ldots \ldots \ldots \ldots$

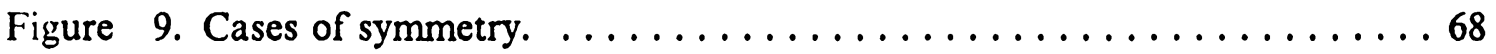

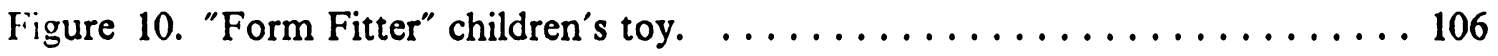

Figure 11. 3-pin electrical adaptor and 3-pin electrical plug. $\ldots \ldots \ldots \ldots 107$ 


\section{INTRODUCTION}

The Rehabilitation Act of 1973, as amended in 1986, defines rehabilitation engineering as the systematic application of technologies, engineering methodologies, or scientific principles to meet the needs of and address the barriers confronted by individuals with handicaps in the areas of education, rehabilitation, employment, transportation, independent living, and recreation (Senate Bill 2515). The term "handicap" is significant in this context. Since there is some confusion about the meaning and controversy in use, the term handicap needs to be further discussed and refined.

According to the World Health Organization (1980); deficiency refers to the medical cause; incapacity defines the functional consequences of the deficiency; and handicap defines the social consequences of the medical and functional factors. Corso (1984) devised a similar definition of terms where impairment refers to an unhealthy or unusual disturbance at the organ which affects the functioning of a bodily system and is acknowledged by the experiencing person; disability reflects the functional consequences of an impairment in the execution of common daily activities; and handicap reflects the social consequences of the impairment in terms of adverse or disadvantageous evaluations attached to a person's performance or status. In both definitions, 
handicap refers to some social consequence. This study adhered to the definitions of Corso and used the term disabled, instead of handicapped, when referring to the population of interest. This is because emphasis was placed on the functional, not the social, consequences. Corso also notes that the medical profession is concerned with the impairment, while social policies and legislation are concerned with handicaps. Rehabilitation concentrates on abilities rather than disabilities and thus provides the link between the medical and social efforts. In reference to the terminology used, a person is disabled in some aspect, but we are concerned with the abilities they possess. The significance of the amendment cited above is that rehabilitation engineering is formally recognized as crucial to the rehabilitation process in general.

A number of different concerns are addressed within rehabilitation. Efforts are made on different levels to aid individuals or a group of persons with the same disability. Aids to daily living, sports equipment, and other leisure-time items are developed to accommodate large numbers of disabled persons. However, on an individual level the design of specific adaptive devices and the procurement of suitable employment are of prime concern. Employment and self-sufficiency are often considered the final goal of rehabilitation. Employment not only makes a more fulfilling life for the individual, but also aids the community by providing an income-earning citizen instead of a welfare dependent one.

The need and desire to employ the disabled is increasing. This is due in great measure to federal legislation, but it also represents the realization that the disabled population can be a valuable source of motivated and productive workers. However, in order for a disabled person to be productive, the individual's disability must be taken into account and the job and workplace designed accordingly. For this to be possible, some type of assessment must be conducted on the individual, the job, or both. 
A variety of assessment techniques are currently commercially marketed. They measure a wide range of traits from psychological profiles, to cognitive processing capabilities, to physical capabilities. Selection of an appropriate technique depends on the individual to be evaluated and the desired utility of the outcome.

\section{History of Rehabilitation and Assessment}

The medical profession, specifically orthopedics, was the first organization concerned with aiding the disabled. In the eighteenth century the first institute for the crippled and the deformed was established. During the nineteenth century the concept of rehabilitation began to develop. In the beginning, the emphasis was just on care for the disabled. Treatment, education, or training were not of concern. Toward the end of the century, medical treatment and vocational training were becoming part of the approach to rehabilitation. During the first half of the twentieth century rehabilitation efforts concentrated on men who were disabled due to military service or war related activities. The main concern of rehabilitation was still medically based with the emphasis on physical restoration and vocational rehabilitation (Goldenson, 1978).

More recently, persons concerned with rehabilitation have become aware that rehabilitation must involve more than the medical effort. In addition to physical and vocational rehabilitation, social and psychological rehabilitation are now seen as integral parts of a complete rehabilitation approach. This requires not only input from medical specialists, but also physical therapists, psychologists, vocational counselors, educational instructors, and engineers. 
As the goals of rehabilitation expand, the need for information about the disabled person increases. The method of gathering this information takes many forms and has continually evolved over the years. The means of information collection depends on the type of information to be compiled. Assessments are typically conducted in one or more of the following areas: cognitive and intellectual functioning, motor skills, vocational skills, academic skills, language and communication skills, personal and social functioning, and adaptive behavior.

\section{Applications of Physical Ability Assessment}

Numerous approaches to job placement and modification have been developed since rehabilitation first became a public concern. Many of the recent approaches are multidisciplinary, combining factors from many different areas to result in a complete program. An integral part of all of these approaches is assessment.

Meier and Deivanayagam (1980) designed a schematic approach to effective employment of a disabled worker (figure 1). The procedure begins with the sensory and psychomotor capabilities of the individual and the task constraints. Next, equipment, aids, and adaptive devices are considered. Finally, physical and environmental limitations are taken into account. All of this is considered in order to design the job and workplace to make the disabled person an effective employee.

Another approach to employing the disabled was laid out by Longmate (1982) (figure 2). This model was developed as a guide for employment and it is stated that there is no rigid set of rules and each case must be considered individually. Longmate's approach begins with an ergonomic task analysis which is the basis for the subsequent 


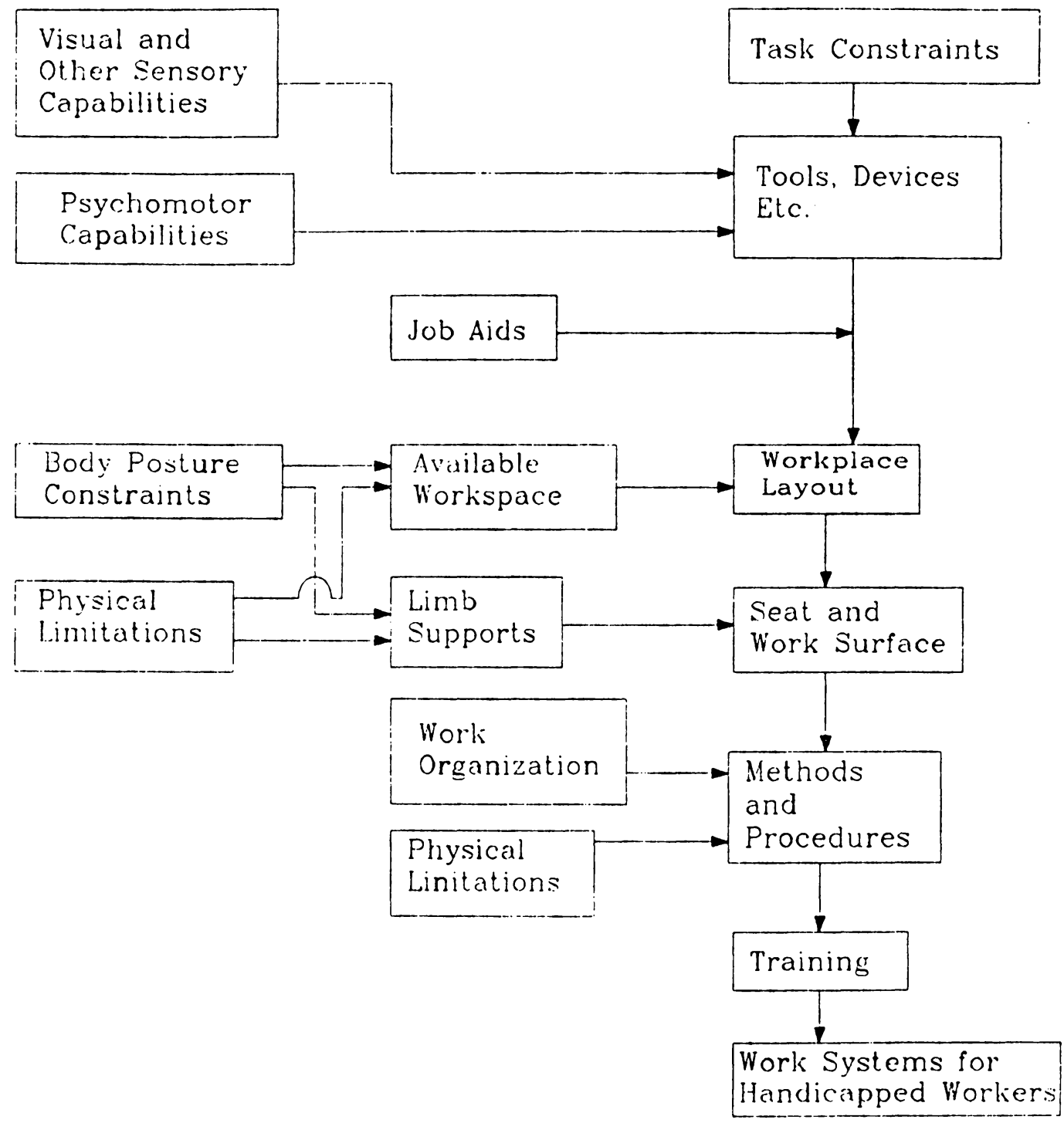

Figure 1. An effective approach to employment 


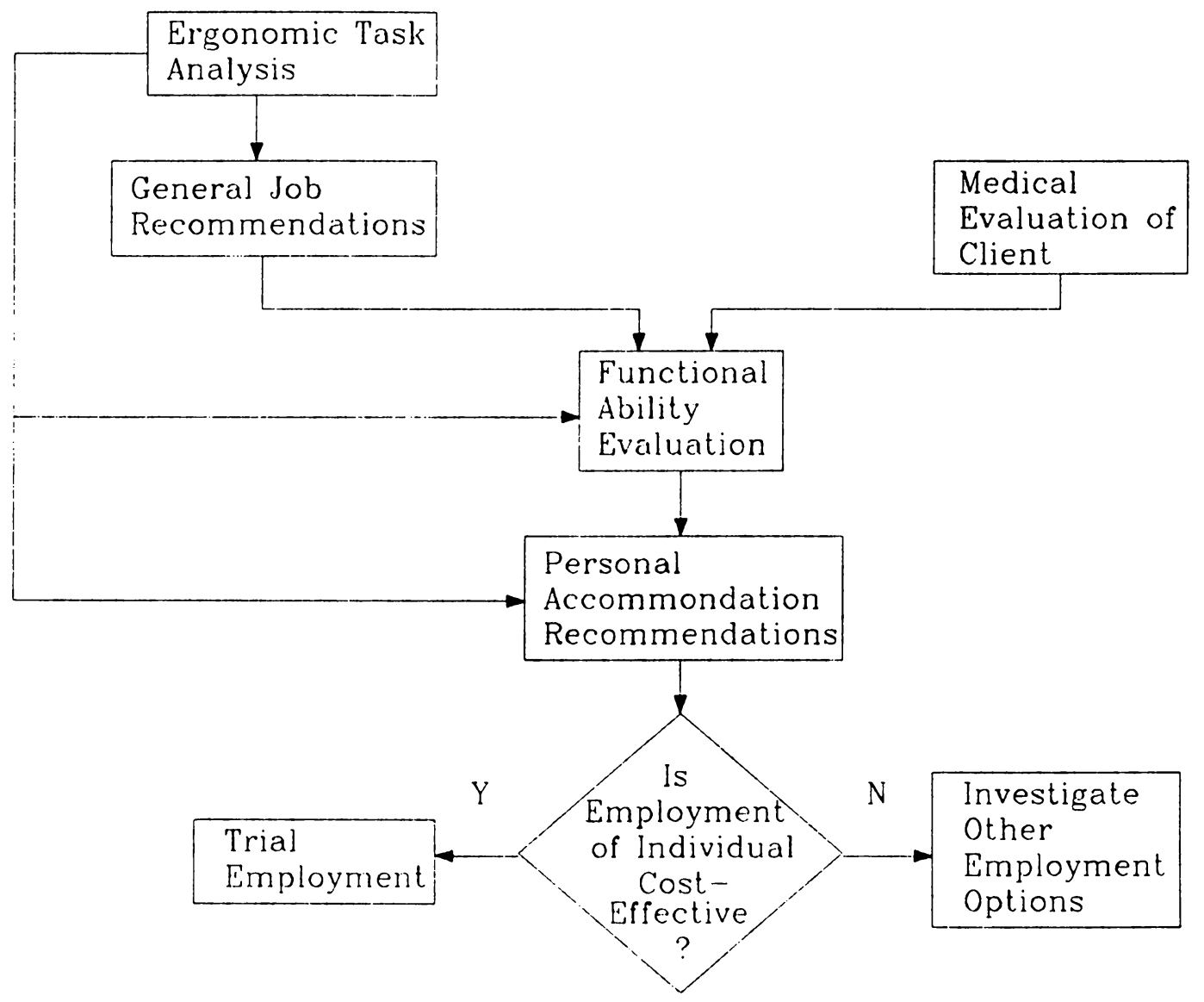

Figure 2. A strategy for employment 
tests in the strategy. It consists of breaking down the job into tasks and then into elements, thus defining the functional requirements of the job. This, along with the general job recommendations, the stressfulness of each element, and the medical evaluation of the person are combined in the functional ability evaluation. Here, the job-related physical abilities of the individual are tested and documented. Personal accommodations are those specifically designed for the individual, such as an adaptive device or change in the work procedure. Finally, taking the information from all the previous steps into account, a decision is made as to whether the individual would be a cost-effective and productive employee in the particular job or position.

Malzahn (1979) states that the philosophical premise behind all modification and task assignment is that the residual abilities of the person are to be optimally utilized. In order to do this, the job's requirements must be matched with the abilities, talents, and aspirations of the individual. Malzahn also states that a quantitative measure of a person's physical capabilities is essential for the job placement or modification.

The job modification approach taken by Malzahn (1982) begins with an analysis of the job to be modified. Motion class analysis is used to define the physical requirements of the tasks contained in the job. Based on the individual's performance in the evaluation, an index of performance is calculated in terms of standard deviations. Standard deviation describes the differences, or dispersion, among all scores. The standard deviation is used to compare the scores of a variable in different distributions. In Malzahn's evaluation the scores of the disabled person are being compared to the scores of able-bodied persons. The mean performance of an able-bodied population is used as the zero point. Therefore, performance exceeding the mean of able-bodied performance will have a positive deviation. Performance which does not meet the mean of able-bodied performance will have a negative deviation. An index exceeding -3.00 
standard deviations indicates that some modification or alteration is necessary in order for the person to perform the job successfully.

A process for job accommodation was presented by Alexander (1986) (figure 3). There are four basic steps to the process. Step 1 ensures that the person has the skills and knowledge to perform the job. Step 2 is assessment of the individual's abilities and the job requirements. If the individual's abilities match those required for the job then no accommodation is necessary. If the they do not match, the process continues. Step 3 includes making the necessary accommodations in the job, equipment, facilities, training, or environment to enable the person to perform the job successfully. Step 4 consists of a trial placement with follow up checks to ensure that the job is being performed to the satisfaction of the employer and employee.

Assessment plays a vital role in each of these approaches. The type of assessment varies according to the needs, but it is always a necessary step in successful job placement or accommodation.

\section{Review of Contemporary Assessment Techniques}

In recent years, a number of assessment techniques, procedures, and apparatus have come into frequent use. Although there are many assessment techniques on the market, the purpose of this overview is to present a small cross-section of what is available. Since the present study is concerned with the physically disabled, only those techniques which concentrate on measuring physical abilities will be discussed. The techniques presented were chosen because of either personal experience with and knowledge of the technique, or on the basis of the general acceptability of the technique. 


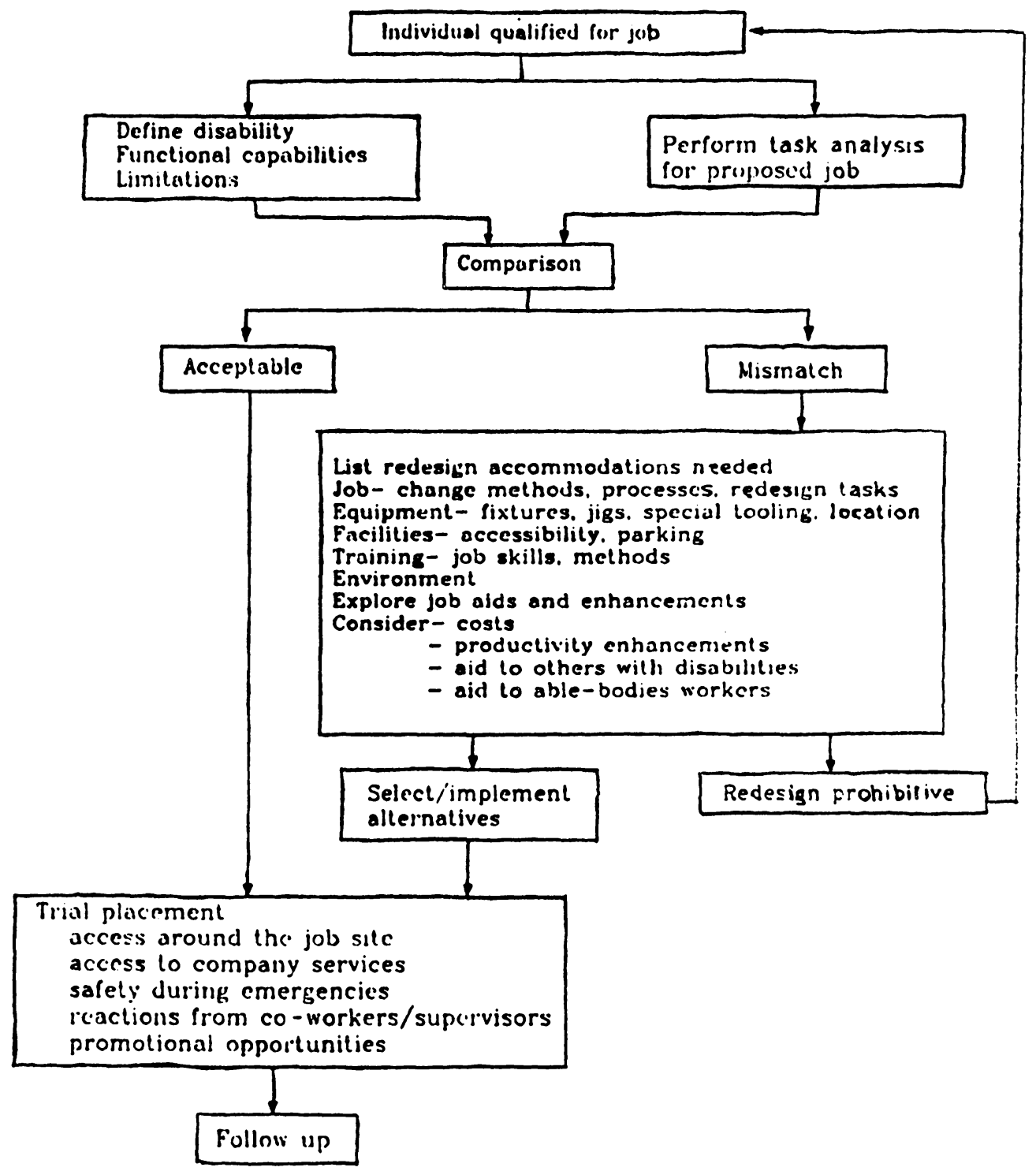

lïgurc 3. Procciss for job accommoslation (Alexander, 1986). 


\section{Available Motions Inventory}

The Available Motions Inventory (AMI) is a series of tests designed to determine the residual capabilities of a disabled person. It samples a variety of physical tasks which are typically required in performing jobs in an industrial setting. The AMI system consists of an assembly substation, a reaction-reach substation, and a special framework which holds test panels (Malzahn, 1979). An assessment with the AMI takes approximately 6 hours.

The procedure employs 71 subtests divided into two main categories: controls and assembly. The controls category is divided into four sections: switches, settings, rate, and strength. Each of the controls tasks is performed in various positions within the framework. The positions include center horizontal, center lower vertical, center upper vertical, side horizontal, and side upper vertical (figure 4). The assembly category consists of nine tasks involving small assembly pieces such as nuts and bolts, and also positioning and drilling operations. Another set of subtests which does not fall into either of the two main categories is the reaction-reach task (Malzahn, 1979).

\section{Workability}

The term Workability was derived from WORKplace capABILITY assessment series. The series was developed from MODAPTS, which is a collection of "natural" speeds for unexceptional performance of tasks (Heyde, 1983).

The Workability series consists of 21 tests ranging from basic physical tasks to cognitive tasks. They are similar to tasks required in a simple industrial setting, through complex industrial work, to office work. The tests were particularly designed to use fa- 


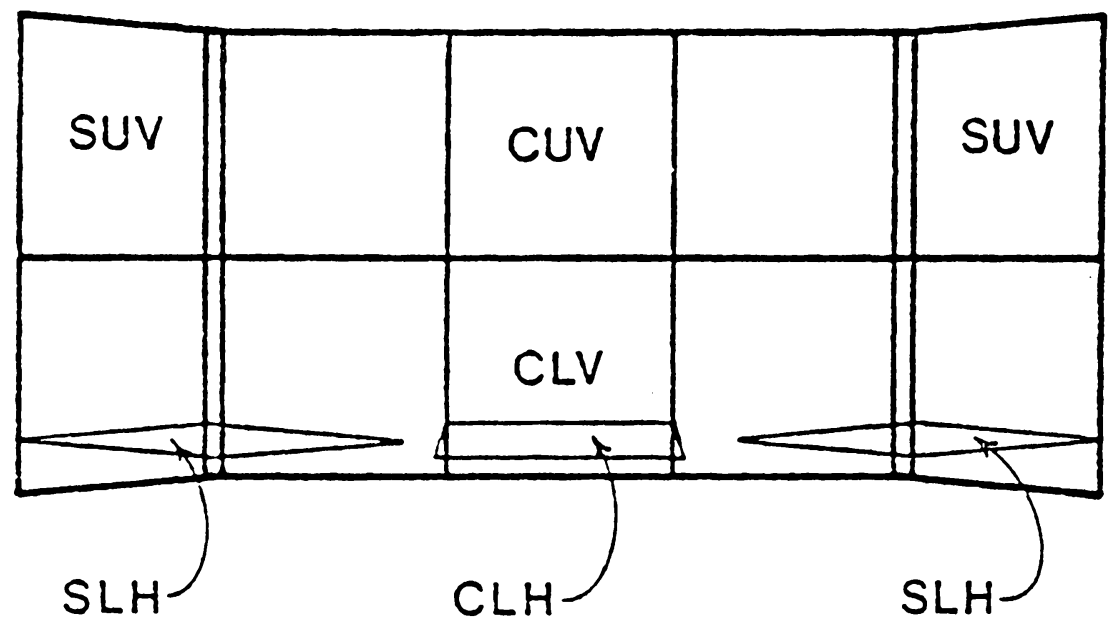

Figure 4. Test panel positions in the A.III framework: side upper vertical (SUV), center upper vertical (CLV), center lower vertical (CLV), side lower horizontal (SLII), and eenter lower horizontal (CLII). 
miliar materials which are inexpensive and easy to acquire. The series begins with tasks such as manipulating marbles and dominoes, and progresses through moving bricks to reading comprehension and simple calculations. A Workability assessment does not require a specific setting. It may be conducted wherever the necessary materials can be compiled and there is adequate space.

\section{WEST-WTS}

Work Evaluation Systems Technology (WEST) developed the Work Tolerance Screening (WTS) devices. WTS consists of 7 devices,(WEST 1, 2, 4, 7, the Comprehensive Weight System, the Tool Sort, and the Multiple-Use Shelf Kit), which may be used alone or in conjunction with one or more of the other devices. The devices require no special setting for use. An evaluation with WTS takes approximately 2 to 4 hours (WEST, 1987).

WEST1 and WEST2, when used in conjunction with other devices, measure upper extremity capacity and whole body range of motion. They may also be used for an assembly/disassembly task. WEST4 measures upper extremity strength and fatigue tolerance in tasks that require pronation/supination or internal/external rotation against resistance. WEST7, the Bus Bench, evaluates manual dexterity and finger dexterity factors. The WEST Comprehensive Weight System, when used in conjunction with other devices, evaluates lifting and carrying capacity. The WEST Tool Sort assists in functional grading of progress in a work program, differentiation of symptomatology from productivity, identification of Type 2 Symptom Magnification Syndrome (malingerer), and vocational exploration. The Multiple-Use Shelf Kit simulates job analysis based lifting demands (WEST, 1987). 


\section{Sensor Pegboard Test Method}

The sensor pegboard test method is designed to evaluate the differences in finger function between disabled and able-bodied persons as well as determine age-related changes in ability. The sensor pegboard assesses manual dexterity on levels ranging from simple to complex and also upper-limb function (Okada, 1985).

The sensor pegboard method consists of 8 tests which result in time values associated with simple motion elements, vocational aptitude, construction of symmetrical figures, color discrimination, and a cybernetical controllability number. The tests are performed on a pegboard which has a touch sensor. The pegs are made of electrically conductive aluminum and are held next to the panel by a square pan which also has a touch sensor. The tests include such tasks as tapping the board, inserting and extracting pegs, and constructing symmetrical figures with the pegs (Okada, 1985).

\section{Vocational Assessment Techniques}

There are numerous assessment techniques which are directed toward specific vocational abilities. Most of these are based on work samples or observations of a person performing a job. For example, the Valpar Component Work Sample Series consists of 16 work samples of such activities as small tool handling, size discrimination, clerical comprehension and aptitude, problem solving, money-handling, and drafting. Performance on each of these activities is timed and rated (Botterbusch, 1980).

Another vocational assessment is the Testing Orientation and Work Evaluation in Rehabilitation (TOWER), which is directed toward the physically and emotionally disabled. This method samples performance in areas similar to Valpar; clerical and 
business arithmetic, drafting, machine shop, and jewelry manufacturing. Performance is timed, rated on a scale, and rated for errors (Botterbusch, 1980). Time to complete the entire assessment is approximately three weeks. Related to this is Micro-TOWER, which is designed for the general rehabilitation population. This also consists of work samples on which performance is timed and rated. Time to complete the assessment is 15 to 20 hours (Botterbusch, 1980).

Talent Assessment Programs (TAP) is not as specific as the previously discussed methods. This assessment samples such activities as structural and mechanical visualization, discrimination of size and shape, fine dexterity with and without tools, and gross dexterity with and without tools (Botterbusch, 1980). These methods of assessment are task specific and some require a fairly high baseline of ability. 


\section{RESEARCH OBJECTIVES}

The objective of this study was to develop a physical ability assessment technique which would overcome some of the difficulties found in the other techniques. Three factors, not found together in any of the existing marketed techniques, were incorporated for this effort. These factors are: one, norm-independence. This means the test does not compare the performance of an individual to a standard established by ablebodied persons. This factor was considered vitally important in the development of the technique, and thus the title of the technique includes the term norm-independent. Two, limitation to a test of manipulation ability. Three, generation of a profile of ability which infers capability to execute a task, or aid in the design of an adaptive device.

The need for such an assessment technique was discovered through experience with some of the existing techniques which are commonly used. The problems encountered with these techniques, along with some of the desirable properties, formed the basis for developing a new technique. The first problem is one of comparing performance on a task to a "normal" performance. For example, the scoring and interpretation of the AMI are based on comparing performance on several subtests by means of uniform ability scales. These scales are generated by setting the mean performance of 
able-bodied subjects as the zero point and one standard deviation of that performance as the unit of measure (Malzahn, 1979). Thus, all scores are compared to those of able-bodied persons. Another example is the Workability assessment where a person is timed when performing a task and that time is compared to "normal" as determined by MODAPTS. The standard MODAPTS times were assigned by trained, able-bodied workers. It is stated that this provides a measure of that person's possible disability in performing the task (Heyde, 1983), not a measure of the person's ability. This practice of comparing an individual's performance to "normal" is of value only in those cases where the extent of the person's disability is mild enough to permit a meaningful comparison.

It may appear that "normal" performance is what is required for employment. This is not necessarily the case. In order for employment to be competitive, an individual must produce at a level equal to or exceeding that of other employees. The manner in which this level of production is achieved should not be of concern. There is often more than one way to accomplish a job and the individual should be allowed to perform in the manner that is most successful for him/her. Individuals should not be denied a job because they do not perform it in the "normal" or conventional manner.

The second problem encountered is that the existing assessments attempt to sample a large variety of abilities and consequently do not result in a complete measure of any ability. For example, part of the AMI evaluation system consists of translating performance scores into motion class scores. However, not all of the motion classes are considered because they do not appear in the AMI subtests (Malzahn, 1982). Workability also attempts to assess such a wide range of behavior, from simple physical motions to cognitive processing, that it does not result in a comprehensive test of either. A problem arises even within the physical ability tasks. They are not testing only one motion at a time, but two or more. Therefore, if a person is unable to perform one 
portion of the task he/she is not given the opportunity to attempt performing subsequent portions of the task.

The third problem is the applicability of the completed evaluation. In some cases the evaluation is not related to the task or problem in question. Others require highly trained personnel in order to interpret the results. Malzahn (1979) states that scores resulting from an AMI evaluation can be interpreted and used by engineers accustomed to designing jobs for the special population, but the scores are not as informative for those who do not have considerable experience in the field. On the other hand, Chyatte and Birdsong (1971) claim that using an MTM approach to assess physical activities results in an evaluation which is easily understood by medical personnel, vocational counselors, industrial engineers, and industrial personnel workers (Chyatte and Birdsong, 1971).

The method of assessment developed in this study is directed toward the severely disabled. There is no set definition for "severely disabled". The term can mean different things in different situations. In this context, it refers to persons who have extensive impairment of manual functioning which prevents them from accomplishing manipulation tasks in the typical manner. This population is the target of this assessment technique because there are few methods of assessment which are beneficial to them. Most all assessments assume a minimum level or baseline of ability. Persons falling below that level cannot be meaningfully assessed. The new assessment technique attempts to be as fundamental as possible and assume a very low baseline of ability.

In addition, to the previously mentioned factors, this assessment technique has two other qualities which can be of great advantage. One, the materials required for the assessment are inexpensive and easy to acquire. This makes the assessment available to schools and sheltered workshops which are on limited budgets. Two, because of the nature of the assessment technique and the materials used, the assessment may be 
conducted almost anywhere. All that is needed is a table, or some similar work surface, and a quiet place. 


\section{BASES FOR DEVELOPMENT}

There are three concepts upon which this new technique was developed. Motion study was the first concept and provided the basic impetus for the others. Some years later, a group of engineers conducting methods evaluation and improvement work developed Methods-Time Measurement. Finally, Project Co-Op demonstrated the utility of applying motion study and Methods-Time Measurement when aiding the disabled. Each of these concepts is discussed in more detail.

\section{Motion Study}

Motion study is the examination of body motions used in performing an operation for the purpose of maximizing efficiency by elimination and simplification of motions, and determination of the most favorable motion sequence (Niebel, 1982).

In the early 1900's, Frank Gilbreth determined 17 fundamental hand motions (therbligs) which are the elements of all operations. Gilbreth called these motions: 
search, select, grasp, reach, move, hold, release, position, preposition, inspect, assemble, disassemble, use, unavoidable delay, avoidable delay, plan, and rest to overcome fatigue.

These motions are briefly described by Niebel (1982) as follows:

Search - the basic operation element employed to locate an object.

Select - takes place when the operator chooses one part over two or more analogous parts.

Grasp - the elemental hand motion of closing the fingers around a part in an operation.

Reach - the motion of an empty hand, without resistance, toward or away from an object.

Move - a hand movement with a load.

Hold - occurs when either hand is supporting or maintaining control of an object while the other hand is doing useful work.

Release - occurs when the aim of the operator is to relinquish control of an object.

Position - the element of work that consists of locating an object so that it will be properly oriented in a specific place.

Pre-position - consists of positioning an object in a predetermined place so that it may be grasped in the position in which it is to be held when needed. 
Inspect - an element included in an operation to assure acceptable quality through a regular check by the person performing the operation.

Assemble - occurs when two mating parts are brought together.

Disassemble - occurs when two mating parts are disunited.

Use - occurs when either or both hands have control of an object during that part of the cycle when productive work is being performed.

Unavoidable Delay - an interruption beyond the control of an operator in the continuity of an operation.

Avoidable Delay - any idle time that occurs during the cycle for which the operator is solely responsible.

Plan - the mental process that occurs when the operator pauses to determine the next action.

Rest - delay that occurs periodically, but not in every cycle. 


\section{Methods-Time Measurement}

Methods-Time Measurement (MTM) is a procedure which analyzes any manual operation or method, reduces it into the basic motions required for performance, and assigns a predetermined time standard. This standard is determined by the nature of the motion and the conditions under which it is performed (Maynard, Stegemerten, and Schwab, 1948).

During the 1940's, Maynard, Stegemerten, and Schwab were attempting to develop a means of applying methods engineering to an operation prior to production. They believed that a strong connection existed between time and motion. This was the origin of MTM. These developers of MTM began by using the therblig as the elemental subdivision for their micromotion studies. The plots of this data did not show any meaningful results. The need for further element subdivision was apparent. Thus, they redefined and further divided the motions based on the conditions which affected the performance of that motion. Time units were then assigned to each motion under each condition (Karger and Bayha, 1987).

Not all of the original 17 therbligs were used in MTM. Those included were reach, grasp, move, turn release, position, and disengage. The originators of MTM also saw the need to include some additional motions. Those added to the procedure were apply pressure, eye usage, body,leg, and foot motions, and simultaneous motions (Karger and Bayha, 1987). 


\section{Project $\mathrm{Co}-\mathrm{Op}$}

Project Co-Op was a federally funded project at the University of Virginia from 1982 to 1985 . It was designed to develop an innovative model for delivering vocational services to severely disabled students (Project Co-Op, 1984). Industrial engineering faculty and staff (P.T. Kemmerling, M.H. Agee, R.D. Dryden, and V.K. Wright) from Virginia Polytechnic Institute and State University participated as consultants on part of this project.

This specific part of the project concerned one severely disabled young woman. The goal of this effort was to successfully employ this individual in a specified job. The approach taken was to determine a suitable method to assess this individual's ability, conduct the assessment, and design and fabricate an adaptive device to aid in performance of the job (P.T. Kemmerling, personal communication, February, 1986).

In this effort, a list was developed to suggest universally recognized descriptors for classifying, measuring, and recording basic motion patterns. These patterns can be used to describe complex behavior. The basic motions included were derived from MTM. The important difference was that the MTM times associated with each of the motions were not considered. 


\section{DEVELOPMENT OF THE TECHNIQUE}

The development of the new technique represents an expansion of an effort instituted by Prof. P.T. Kemmerling while a consultant to Project Co-Op. This effort was to establish a behavior profile, or range of behavior, that an individual is able to perform based on motion descriptors.

In the present effort, the work affiliated with Project Co-Op was studied as much as possible, although the complete data was not released. As in Project Co-Op, not all of the motions defined by MTM were used and some additional motions were included. Selection of those motions pertinent to the study was made based on the utility of the motion in daily living and employment settings. Each motion was examined closely to determine its function and frequency of use in common activities. Reach, Move, Grasp, Position, Release, and Disengage were selected on the basis of their integral part of daily functioning and the frequency of their occurrence. Apply Pressure is a frequently occurring motion, but it covers a vast number of conditions and to test all of them would be time consuming. Therefore, Apply Pressure was eliminated as a separate test. However, it exists inherently in many of the motions that were selected. Eye Travel and Focus was 
eliminated due to the complexity of testing. Also, it is included in MTM merely as an additional time factor. As in Project Co-Op, the MTM times are not considered, therefore this motion would be meaningless. Body, Leg and Foot Motions were eliminated because, as will be explained later, the new technique is not limbspecific. Simultaneous Motions were eliminated due to the complexity of the motions. This technique attempts to keep the motions as fundamental as possible. Two motions were added to this list of selected motions. A second case of Turn was added to include the motion where the axis of the appendage performing the motion is perpendicular to the axis of rotation. MTM defines this motion as a series of Grasp-Move-Regrasp-etc. However, in other areas of research such as biomechanics, and in domestic nomenclature, this motion is defined as a Turn. Engage was added as the opposite to disengage as many tasks require the performance of both motions.

Descriptors were constructed for each of the motions. These descriptors are not limb-specific. The motion terms describe the result of an action, not the means of performance. Therefore, the motions can be performed by any appendage, defined as a hand, arm, leg, foot, headstick, mouthstick, or any extension of the body which the individual can use for manipulation. There also is no time standard associated with the motion descriptors.

Also included in the preliminary steps was the design of a pre-assessment screening device (see Appendix A within Appendix 1A). Its purpose is to aid in determining an appropriate method of assessment for the individual. No single method of assessment is suitable for the abilities of all individuals. Prior to administration of an assessment, the administrator needs to determine if the technique is compatible with, and will be advantageous to, the individual. If the technique 
is determined to be unsuitable, other techniques should be investigated and considered.

The screening device consists of a two-part questionnaire. The questions are to be answered by the individual if possible. If the individual is not able, the answers should be provided by a family member, guardian, aide/attendant, physician, or other responsible party. The first part of the questionnaire gathers information about the individual's condition and abilities. Questions concern stability of the individual's condition, means of mobility, general manipulation abilities, communication abilities, and any medical needs. These topics were selected because they affect the administration and outcome of an assessment. The second part gathers information about the individual's manipulation abilities. The questions cover the individual's ability to perform specific fundamental motions. Examples are given of tasks which require the performance of fundamental motions at a moderate level. The response is based on the perceived ability of the individual to demonstrate these motions. The individual answers these according to his/her experience or the observation of a responsible party. No testing of abilities is required at this point.

The next step consisted of designing tasks which, when executed, exemplify the motion descriptors. For this, the procedure employed by Project Co-Op was followed. For each motion descriptor, a number of common tasks which demonstrate it were considered. One task for each descriptor was selected based on simplicity of performance, and the item or object used in its performance. The items or objects played an important role because one of the desired goals of this technique was to keep the materials easily available and familiar to most individuals.

Included in this step was the determination of the work envelope within which the tasks are performed. This envelope was based on the horizontal areas 
covered by reach and move as defined by Karger and Bayha (1987) (figure 5). A vertical component was added to this envelope. Based on previous experience with the assessment of a disabled individual, the need for this was apparent. Finally, the constraints for successful and unsuccessful (spastic or uncontrolled) performance of a task were defined. Successful completion of a task was determined to be conscious, intentional and repeatable. This was defined as a motion which the individual recognizes he/she has made, is a motion the individual intended to make, and a motion which the individual could voluntarily perform again. In contrast, a spastic or uncontrolled motion is one which the individual did not recognize he/she had made, did not intend to make, or could not voluntarily perform again.

The final step was the construction of the instruction manual for the evaluator. In order to do this the instructions for administering and scoring an assessment had to be standardized. The instructions specify the motion descriptor, the objective for testing the motion, the materials required for testing, the appendage with which to begin testing, and the execution of the task. In developing the scoring procedure, all possibilities of motion execution were taken into account. This ranged from successful execution, to accidental execution, to no attempt at execution. Codes for identifying this information were assigned as well as forms for recording the information. The intention was to make the manual a complete source of information about the technique so that a person wishing to administer an assessment would not have to attend a training class. The goal was to allow the technique to be a self-taught method and avoid the time and expense of a special training session. 


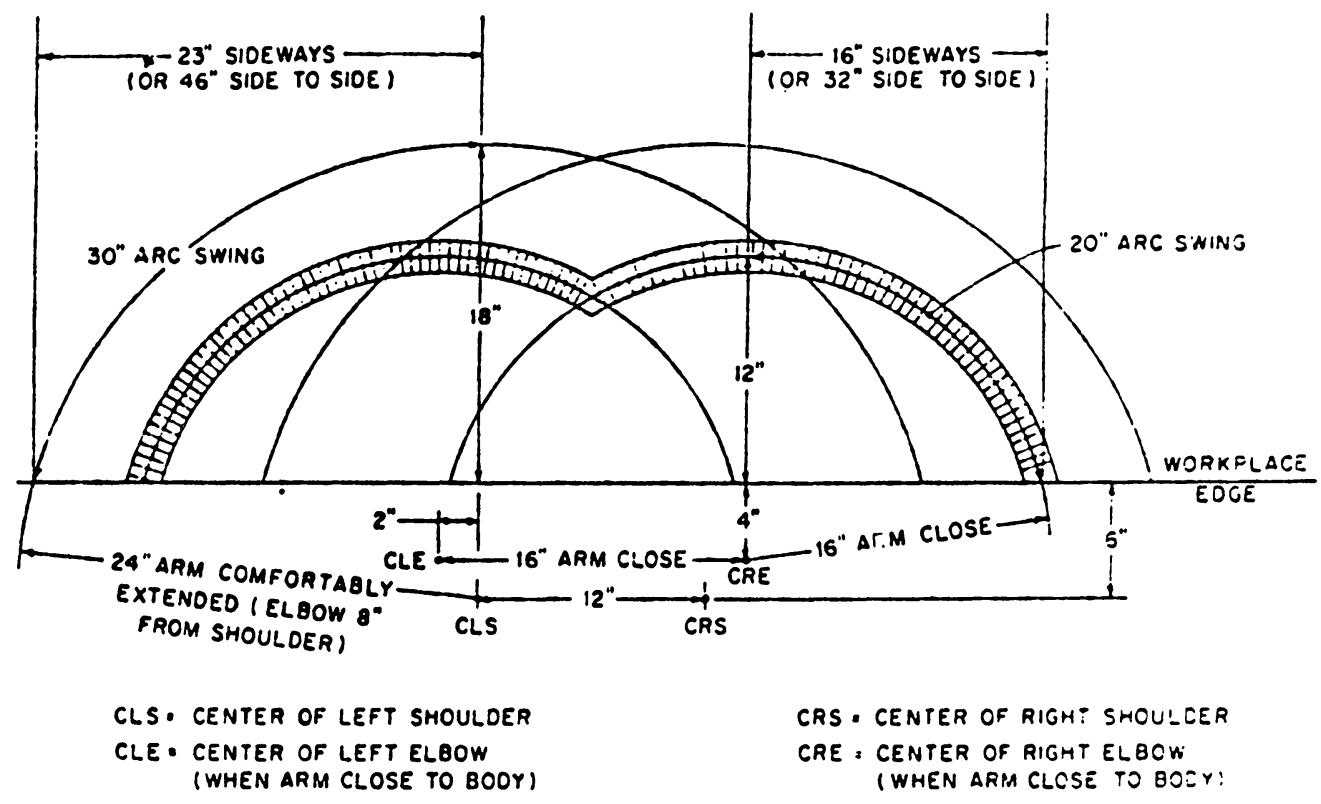

Figure 5. Areas covered by reach and move (Karger and Bayha, 1987). 


\section{RESULTS}

This project resulted in the development of an innovative technique for assessing the physical ability of severely disabled individuals. This technique possesses a number of distinguishing and desirable factors. These include: 1) it is norm-independent, 2) it is limited to a test of manipulation ability, 3) it generates a profile of physical ability, 4) it uses common, inexpensive materials, and 5) the evaluator is not required to attend a specific training course prior to administering an assessment.

The results are compiled in the instruction manual (see Appendix 1A). This is a step-by-step guide through the complete assessment procedure. There are five sections in the manual which represent the five areas in understanding and administering an assessment by this technique. First is the Introduction. This is an overview and discusses some of the development of the technique. A glossary of frequently used terms is also provided.

Second is the Pre-Assessment Phase which first discusses the administration of the Pre-Assessment Information questionnaires. It includes the importance of 
conducting a pre-assessment screening and tips for administering the questionnaires. It also includes the guidelines for interpreting a completed questionnaire. The third section is the Assessment Phase. This begins with some general guidelines on administering the assessment. Then, the bases and procedures for the assessment are presented. This includes the motion descriptors, the objectives for testing the motions, the materials needed to test the motions, and the procedure for testing the motions.

The fourth section is the Post-Assessment Phase. This discusses interpreting and applying the results. Guidelines for compiling and interpreting the resultant profile are given. Means of applying the results are then discussed.

Finally, the fifth section consists of the appendices (see appendices A,B, and C within Appendix 1A), which contain forms and information not included in the main phases of the procedure, but which are necessary in order to administer an assessment. These include the pre-assessment information questionnaires, evaluation forms, and a list of required materials. 


\section{DISCUSSION}

The Norm-Independent Assessment Technique has advantages over many of the other methods of assessment due to the incorporation of three important factors. These are 1)norm-independence, 2) limitation to a test of manipulation ability, and 3) generation of a profile of ability. Because it is norm-independent, a disabled person is not compared to an able bodied person. This results in a measure of ability rather than disability. A measure of what individuals are capable of doing, instead of what they are not capable of doing, is apparently more beneficial for means of employment. Since one of the main reasons for assessing an individual's physical ability is to aid in procuring suitable employment, this is seen as a great advantage. It seems unfair to expect a disabled person to perform a task in the same manner as an able-bodied person. Many disabled persons have creatively and innovatively managed to overcome some of the limiting factors of their disability. They should be allowed to utilize this ability.

Limitation to a test of manipulation ability is also important. Although this does not give much indication of an individual's mental capability (except to follow instructions and distinguish some objects and shapes) or psychological make-up, it 
results in a fairly complete indication of the individuals physical ability. While these other types of information may be useful, an assessment which tries to cover a small part of all types of information does not give a true picture of any one aspect.

The norm-independent assessment results in a profile of the individual's manipulation capability. This represents fundamental abilities, not the ability to perform a specific task. However, from the profile it is possible to infer that individual's capability to execute a specific task. A task would first need to be broken down into the fundamental motions required for performance. Then a comparison could be made between the required motions and those motions the individual is able to perform. The profile may also be used to design an adaptive device to aid in daily living or employment by following a similar procedure. In addition, given this profile, it should be possible to infer performance or fabricate adaptations without having to actually see the disabled individual. This would be a great advantage because it allows an assessment to be conducted at a location convenient to the individual and the profile may then be sent to a prospective employer or an engineer specializing in the design of devices for the disabled.

The materials used for the assessment were selected for a number of reasons. First, they are common, inexpensive items. Therefore, they are available in most locations and purchase incurs only a minimal expense. Sheltered workshops and schools dealing with disabled persons often wish to assess individuals, but cannot afford the expense of many of the marketed techniques. The price of some of the more commonly used techniques ranges from $\$ 1000$ to over $\$ 50,000$ (Botterbusch, 1980). The new technique would work well within the limited budgets of such places. The cost of the materials is under $\$ 50$. Second, the items are familiar to most individuals. Some assessments use large frameworks or unusual 
apparatus which can be intimidating. There have been cases where the individual's true ability was not expressed merely because the equipment used for the assessment frightened them (Leah Ross, personal communication, April, 1986). Familiar items may give the individual more confidence. A task may be one that the individual has performed many times before, but if asked to perform this same task in an unusual setting he/she may perceive it as more difficult. Third, it takes little space to conduct an assessment by this means. It may be administered anywhere from a private home, to a class room, to an office or industrial setting. Fourth, this assessment takes relatively little time. It is estimated that most assessments should take approximately four hours. Some of the marketed techniques can span over days to months (Botterbusch, 1980).

The norm-independent assessment is simple and easy to administer. This eliminates the need for the evaluator to attend a time consuming and expensive training program. The instruction manual contains all the necessary information. A few hours spent studying the manual should enable a person to administer an assessment. 


\section{REFERENCES}

Alexander, D. C. (1986). The practice and management of industrial ergonomics. Englewood Cliffs, NJ: Prentice-Hall, Inc.

Botterbusch, K. F. (1980). A comparison of commercial vocational evaluation systems. Stout, WI: Materials Development Center, Stout Vocational Rehabilitation Institute, University of Wisconsin.

Chyatte, S. B. and Birdsong, J. H. (1971). Predetermined motion time techniques as a medical measurement system. AIIE transactions : Industrial Engineering Research and Development, 3 (3), 206-211.

Corso, J. F. (1984). Human factors in medical rehabilitation: some major problem areas. In Proceeding of the Human Factors Society 28th Annual Meeting (pp. 649-652). Santa Monica, CA: Human Factors Society.

Goldenson, R. M. (1978). Dimensions of the field. In R. Goldenson, J. R. Dunham, and C. S. Dunham (Eds.), Disability and Rehabilitation Handbook, (pp. 3-11). New York: McGraw-Hill.

Heyde, G. C. (1983) MODAPTS plus. Heyde Dynamics Pty. Ltd. Sydney, Australia..

Karger, D. W. and Bayha, F. H. (1987). Engineered work measurement (2nd ed.). New York NY: Industrial Press.

Longmate, A. R. (1982). Employment of physically limited persons. In Proceedings of the Institute of Industrial Engineers Annual Industrial Engineering Conference (pp. 188-193). Norcross, GA: IIE.

Malzahn, D. (1979). Ability evaluation and job modification for the severely disabled. In Proceedings of the American Institute of Industrial Engineers Spring Annual Conference (pp. 44-51). Norcross, GA: AIIE. 
Malzahn, D. (1982). Job modification and placement strategies for person's with physical disabilities using the Available Motions Inventory. In Proceedings of the American Institute of Industrial Engineers Annual Industrial Engineering Conference (pp. 179-187). Norcross, GA: AllE.

Maynard, H. B., Stegemerten, G. J., and Schwab, J. L. (1948). Methods- Time Measurement. New York,NY: McGraw-Hill Co..

Meier, F. A. and Deivanayagam, S. (1980). A study of job design to improve the productivity of severely handicapped workers. In Proceedings of the American Institute of Industrial Engineers Spring Annual Conference (pp. 84-87). Norcross, GA: AIIE.

Neibel, B. W. (1982). Motion and time study(7th ed.). Homewood, Il: Richard D. Irwin, Inc.

Okada, Y. (1985). Evaluation of upper-limb function by the sensor pegboard test method. Ergonomics, 28,(6), 915-927.

Project Co-Op (1984). Project Co-Op News, Spring 1984. Charlottesville, VA: University of Virginia.

WEST (1987). Work evaluation systems technology. Huntington Beach, CA: WEST

World Health Organization (1980).International classification of impairments, disabilities, and handicaps: a manual of classification relating to the consequences of disease. Geneve. 


\section{APPENDIX 1A}

\section{INSTRUCTION MANUAL}

\section{INTRODUCTION}

This instruction manual is designed to take you step-by-step through the assessment procedure. It is recommended that you read the entire instruction manual and understand it completely before administering an assessment. This manual is divided into four main sections. The Introduction gives you an overview and discusses some of the development of the assessment procedure. Next, the Pre-Assessment phase is discussed. Following that, the Assessment Phase discusses the bases of the assessment and the procedures are explained. The Post-Assessment Phase gives advice about interpreting and applying the results. Finally, the Appendix contains copies of forms which are used for the assessment and a compiled list of necessary materials.

There are three characteristics which set this method of assessment apart from the others. First, it is norm-independent, it does not compare the performance of a disabled person to a standard established by able-bodied persons. Second, it 
is limited to a comprehensive test of manipulation ability. Third, it generates a profile of ability. The significance of this last characteristic will be apparent later when the interpretation and application of the results are discussed.

This assessment technique was designed with both the disabled individual and the evaluator in mind. For the disabled individual the tasks were designed to be as fundamental as possible. The materials used to perform the tasks were selected because of their common presence and familiarity to most persons. This is an attempt to keep the individuals from being intimidated, as can often happen when they are confronted by large or unfamiliar equipment.

For the evaluator, the tasks were designed to be simple to understand and administer. This instruction manual was constructed to take you through each step of the assessment procedure. This was chosen in lieu of a time consuming and costly training program.

For both parties concerned, this technique was designed to require a minimal amount of time and monetary expense. The materials needed to administer an assessment are inexpensive as well as being easily obtainable. It is estimated that an assessment can be completed within approximately four hours.

\section{Frequently Used Terms}

Throughout this manual there will be some terms which are frequently used, but with which you may not be familiar. These terms are defined here.

appendage - an arm, hand, leg, foot, headstick, mouthstick, or any extension of the body which is used for manipulation. 
conscious, intentional, and repeatable motion - a motion which the individual recognizes he/she has made, is a motion the individual intended to make, and a motion which the individual could voluntarily perform again.

dominant or preferred appendage - the appendage which is strongest or used most. This may be determined by asking the individual or a responsible party.

Fundamental motion - the basic divisions of which all manual operations are made.

spastic or uncontrolled motion - a motion which the individual did not did not realize he/she had made, a motion the individual did not intend to make, or a motion which the individual could not voluntarily perform again.

\section{THE PRE-ASSESSMENT PHASE}

\section{Administration of the Pre-Assessment Questionnaires}

Once you have decided to evaluate an individual's physical ability, there is still another important decision to be made. Which method of assessment you use is crucial to the outcome and the utility of the completed assessment. The Pre-Assessment Phase presented here is designed to aid you in making that decision. It consists of a two part questionnaire. This will give you the background information on the individual which can help you to make an educated decision.

The pre-assessment questionnaires are found in the Appendix A. It is suggested that you make photo-copies of the questionnaires on which to write so that you retain 
a clean copy for future use. If the individual is not able to answer the questionnaires, they should be answered by a family member, guardian, aide/attendant, physician, or other responsible person. This should be determined in advance so that an appropriate person is available to answer the questions. Initially, only the first part of the questionnaire should be administered. Based on the interpretation of the answers, the second part can be administered or the individual can be dismissed because of incompatibility with this assessment technique. 
Interpreting the Pre-Assessment Information Questionnaires (Part I)

Part I of the questionnaire is designed to aid in determining the appropriate method of assessment for the individual by gathering general information about the individual's condition and abilities. The method presented here may be too fundamental or too advanced for a particular individual. The pre-assessment questionnaire will provide information to help make this decision. Recommendations for a more suitable method of assessment, where applicable, will also be noted.

The following guidelines will give suggested conclusions, advice, and recommendations. to be made based on an individual's responses to the pre-assessment questions.

1. Question 1 pertains to the state of the individual's condition. If the individual's condition is deteriorating it should be noted that the results of any assessment, and subsequent decisions based on the assessment, may not hold true at a future time.

2. Question 2 identifies the classification of the individual's disability. Individuals with more than minimal mental retardation may not be well suited to this method of assessment due to the required comprehension of instructions.

3. Questions 3, 4, 5, and 6 pertain to general information about the individual. This information is beneficial in adjusting the procedure for administering the assessment to the individual. 
4. Question 7 concerns the individual's ability to communicate with other persons. A yes/no response can be anything from verbal response to an eye blink or puff of air. The criterion is that the individual must respond in this manner consistently.

5. Questions 8 and 9 pertain to the individual's ability to manipulate objects. Typically, manipulation is performed by the fingers, hands, and arms. However, these questions consider any manner in which the individual can manipulate objects. This can be achieved by feet, legs, headstick, mouthstick or any other extension of the body.

6. Question 10 concerns the individual's ability to understand and follow instructions. This is important as the individual must follow instructions in order to participate in the assessment.

7. If the answers to questions $7,8,9$, and 10 are 'no', it is suggested that a more qualitative form of assessment would be beneficial to the individual. A Comparison of Commercial Vocational Evaluation Systems by K. F. Botterbusch gives descriptions of some methods of assessment which may be useful.

8. Question 11 is for any additional information which may affect the administration or outcome of an assessment. For example, if the individual can sit still for only a short period of time, the assessment will need to be administered with frequent rest breaks. If the individual normally requires an aide or attendant, one will need to be present. These conditions will be different for each individual.

9. Based on the information you have collected thus far, you should be able to make a decision as to whether or not this method of assessment could possibly be suit- 
able to the individual. If you believe it may be well suited to the individual, then administer Part II of the Pre-Assessment Questionnaire. 
Interpreting the Pre-Assessment Information Questionnaire (Part II)

The questions in this part are designed to give a general overview of the types of manipulation tasks the individual is capable of performing. The answers are based solely on the experience of the individual or the observation of the responsible party answering the questionnaire.

The following guidelines will give suggested conclusions, advice, and recommendations to be made based on an individual's responses to the pre-assessment questions.

1. If the answer to ten* or more questions is 'no', it is possible that a more qualitative form of assessment would be beneficial to the individual. Consult $A$. Comparison of Vocational Evaluation Systems by K. F. Botterbusch for descriptions of some assessment techniques which may be suitable.

2. If the answer to ten* or more questions is 'yes', it is possible that a more quantitative form of assessment would be beneficial to the individual. The Available Motions Inventory (AMI) or Workability are two suggestions.

3. If the individual has a level of manipulation ability somewhere between the extremes, this technique is a good candidate for the method of assessment to use with the individual. Proceed to the Assessment Phase.

* Ten is a suggested cut-off, subject to your own discretion. The purpose of this questionnaire is to aid in identifying those individuals with very low or very high levels of 
ability. It may be beneficial to use an alternate method of assessment for those individuals.

\section{THE ASSESSMENT PHASE}

\section{General Guidelines on Assessment}

This assessment technique is based on motion descriptors. Eight motions were selected for assessment based on their utility and frequency of use in daily living and employment settings. The motions selected are Reach, Grasp, Release, Move, Turn, Position, Engage, and Disengage. The assessment procedure is divided into six sections. Each section is organized in the same manner. First, the motion, or motions, is/are defined and the objective for testing the motion is stated. The materials necessary to test the motion are then listed. This is followed by the procedure for testing the motion. Evaluation forms and guidelines for evaluating performance are included in the Appendix. If you are unfamiliar with the motion descriptors, it is suggested that you read the definitions at this time. This will help you to understand the subsequent discussions.

The specific procedure for administering each of the tests will be discussed later; these are just some overall guidelines and tips you should follow when administering an assessment.

- The materials listed are guidelines. You may substitute a similar object if necessary. The important point is to uphold the objective of the test and the case of motion being tested. 
-There is no one set way of performing a motion. Allow the individual to do what is easiest and most successful as long as it is in keeping with the objective.

- Try to keep the individual on a schedule as close as possible to the one typically followed during a normal day, such as meal and rest times.

-If an aid or attendant is normally required make sure one is present.

-Allow the subject to take breaks as necessary, but try to complete a test before resting.

-Make notes of all events that occur pertaining to the individual's performance or behavior. For example, the manner in which a motion is performed, if the individual is easily distracted from the task at hand, if frequent breaks are required - anything that may be informative at a later time. Space is left on the evaluation forms to write notes.

- The Evaluation forms are in Appendix B. It is suggested that you make photocopies of the evaluation forms on which to write. That way you will retain a fresh copy for future use. 


\section{Reach}

Reach is the basic motion employed when the predominant purpose is to move the appendage toward an object or destination which will enable performance of the next motion.

Objective for Testing Reach

The objective for testing Reach is to determine the outer limits which an individual can access within a typical work space.

Materials Required to Test Reach

(see Appendix C for specifics)

- horizontal work surface at least $58^{\prime \prime} \times 20^{\prime \prime}$

- *Reach Mat

- *Reach Arc

- Yardstick

- *Reach Evaluation form

- optional: a plastic checker

* Items provided with the manual. 
1. Answer question 1 on the Reach Evaluation form.

2. Position the individual so that the work surface is comfortably accessible by the appendage to be used. Answer question 2 on the Reach Evaluation form.

3. Place the Reach Mat on the work surface at the edge closest to the individual. Place the Mat so that the 'center body' line aligns with the vertical center of the individual's torso. If possible, align the 'center shoulder' lines with the individual's shoulders.

4. Answer question 3 on the Reach Evaluation form.

5. If two appendages will be tested, begin with the dominant or preferred appendage. Indicate on the first Chart which appendage is being tested by circling the appropriate letter; L-left, C-center, R-right.

6. Place the Reach Arc on the Mat at the edge closest to the individual. The words 'Reach Arc' should be farthest from the individual. If a right appendage will be tested first align the 'right side' lines of the Mat and Arc. Align 'left side' lines to test a left appendage. Align 'center body' lines for a center appendage.

7. The Arc is marked in degrees and inches. The curved arcs appear every 2 inches. The straight lines appear every 10 degrees. The important points will be the intersections of the lines and arcs. 
Begin with the $18^{\prime \prime}$ arc.

8. Ask the individual to touch the $20^{\circ}$ right, $90^{\circ}$, and 20 left points on the arc. You may indicate to the individual where the point is or place the checker over the point. After the individual attempts each Reach, record the result by placing the appropriate letter in the corresponding box on the chart. The evaluation code is explained on the form.

- if all three Reaches are successfully completed (X), go to step 10.

- if none of the three Reaches are successfully completed (O), return to step 8 , use the next smaller arc and proceed again.

- if one or two of the Reaches are successfully completed, go to step 9.

9. Begin at the point which was successfully reached. Proceed to the next $10^{Q}$ increment towards the point that was not successfully reached. Ask the individual to touch the point. Record the result.

- if the Reach was successfully completed (X), return to step 9 and proceed again.

- if the Reach was not successfully completed $(0)$, return to step 8 , use the next smaller arc and proceed again.

10. If two appendages are being tested, align the Arc on the other side. Indicate on the second Chart which appendage is being tested. Return to step 8 and repeat the procedure. If both appendages have been tested, proceed to the Vertical Reach tests. 
1. The individual should be positioned the same as for the Horizontal Reach test.

2. Vertical Reach will be measured at the outer points which the individual could successfully reach horizontally.

3. Begin with the appendage last tested. Indicate this appendage on the first Vertical Reach Chart.

4. Stand the yardstick vertically at the outer-most point reached on the side of the appendage being tested. The 1 " end of the stick should be toward the work surface.

5. Ask the individual to touch the highest point possible on the yardstick. Record the position of the stick and the height which the individual touched on the Chart.

6. Move the yardstick to the next point along the outer edge of the individual's horizontal reach range. Return to step 5 and proceed until all outer point have been measured.

7. When all outer points have been measured, move the Arc to the side of the other appendage to be tested. Repeat the procedure.

8. When testing is complete, remove the Arc and Mat from the work surface.

Be sure to make notes of anything that pertains to the individual's performance or behavior. 


\section{Grasp and Release}

Grasp and Release will be discussed and tested together since a Release is contingent on a prior Grasp.

Grasp is the basic motion employed to obtain control of an object.

- The appendage must obtain sufficient control of the object to be able to perform the next basic motion.

\section{Cases of Grasp}

Case 1A- Obtain control of a small, medium, or large object by itself, easily grasped.

Case 1B-Obtain control of a single object of very small size in an isolated location or a thin object whose surface contacts closely a flat supporting surface.

Case 1C- Obtain control of a single object approximating a cylindrical shape which contacts it surroundings with one longitudinal surface other than the one on which it rests.

1C1- object has diameter larger than $1 / 2^{\prime \prime}$.

1C2- object has diameter $1 / 4^{\prime \prime}$ to $1 / 2^{\prime \prime}$.

1C3- object has diameter less than $1 / 4^{\prime \prime}$.

Case 2- Grasp used to shift the hold on an object already under control or to improve or increase control of the object.

Case 3- Grasp used to transfer an object from one appendage to another when the shift involves brief holding of the object by both appendages. 
Case 4- Obtain control of a single object from a jumbled pile of objects when the act of search and select must occur.

$4 \mathrm{~A}$ - object larger than $1^{\prime \prime} \times 1^{\prime \prime} \times 1^{\prime \prime}$.

$4 B$ - object $1 / 4^{\prime \prime} \times 1 / 4^{\prime \prime} \times 1 / 8^{\prime \prime}$ to $1^{\prime \prime} \times 1^{\prime \prime} \times 1^{\prime \prime}$.

$4 C$ - object smaller than $1 / 4^{\prime \prime} \times 1 / 4^{\prime \prime} \times 1 / 8^{\prime \prime}$.

Case 5- Grasp used when enough control of a single object is gained merely by purposeful contact of the object surface by the appendage.

Release is the basic motion employed to relinquish control of an object.

\section{Objective for Testing Grasp and Release}

The objective for testing Grasp and Release is to determine some of the different sizes and shapes of objects over which the individual can obtain and relinquish control.

Materials Required to Test Grasp and Release

(see Appendix C for specifics)

- horizontal work surface

- a toy block

- a washer

- three spools of thread.

- three pencils

- three toothpicks 
- a pencil with an eraser.

- **six table-tennis balls, a bowl to hold them

- **twelve marbles, a bowl to hold them

- **twelve b-b's, a bowl to hold them

- a cardboard box

- Grasp Evaluation form

* Items provided with the manual.

** These quantities are only a suggestion. The objective is for the individual to select one object from a number of objects which are together. The bowls should be large enough to hold the objects, but not so large that the individual needs to reach down into the bowl.

Procedure for Testing Grasp and Release

1. Answer questions 1 and 2 on the Grasp Evaluation form.

2. Position the individual so that the work surface is comfortably accessible by the appendage to be tested.

3. If two appendages will be tested, begin testing with the dominant or preferred appendage. Indicate this by circling the appropriate letter on the first chart; L-left, Ccenter, R-right. 
4. To test the individual's ability to execute a case 1A Grasp, place the toy block on the work surface.

NOTE: Unless otherwise specified, place objects on the work surface at a location easily accessible to the individual.

5. Ask the individual to pick up the object. Record the result by placing the appropriate letter in the corresponding box in the Grasp Chart. The evaluation code is explained on the form. Ask the individual to release control of the object. Record the result.

6. Indicate the other appendage on the second Grasp Chart. Repeat the procedure for that appendage.

7. Remove the object from the work area.

8. To test the ability to execute a case IB Grasp, place the washer or dime flat on the work surface.

9. Ask the individual to pick up the object. Record the result. Ask the individual to release the object. Record the result.

10. Repeat the procedure for the other appendage.

11. Remove the object from the work surface. 
12. To test the ability to execute a case $1 \mathrm{Cl}$ Grasp, place three spools on the work surface next to each other (see figure 6).

13. Ask the individual to pick up the closest object. Record the result. Ask the individual to release the object. Record the result.

14. Repeat the procedure for the other appendage.

15. Remove the objects from the work surface.

16. To test the ability to execute a case $1 \mathrm{C} 2$ Grasp, place three pencils on the work surface next to each other (see figure 7).

17. Ask the individual to pick up the closest object. Record the result. Ask the individual to release the object. Record the result.

18. Repeat the procedure for the other appendage.

19. Remove the objects from the work surface.

20. To test the ability to execute a case IC3 Grasp place three toothpicks on the work surface (see figure 8 ).

21. Ask the individual to pick up the closest object. Record the result. Ask the individual to release the object. Record the result. 
22. Repeat the procedure for the other appendage.

23. Remove the objects from the work surface.

24 . To test the ability to perform a case 2 Grasp, place a pencil on the work surface.

25. Ask the individual to pick up the pencil at the writing end. After the object is under control, ask the individual to shift the pencil such as to use the eraser end. Record the result. Ask the individual to release the object. Record the result.

26. Repeat the procedure for the other appendage.

27. Remove the object from the work surface.

NOTE: If only one appendage is being tested it will not be possible to execute a transfer Grasp.

28. Select an object which the individual has previously used and could easily control.

29. Begin by having the individual grasp the object with the dominant appendage. After the object is under control, ask the individual to transfer the object to the other appendage and control the object. Record the result.

30. Repeat the procedure beginning with the non-dominant appendage.

31. Remove the object from the work surface. 
32. To test the ability to perform a case $4 \mathrm{~A}$ Grasp, place the bowl, filled with the table tennis balls, on the work surface.

33. Ask the individual to remove one ball from the bowl. Record the results. Ask the individual to put the ball back in the bowl. Record the result.

34. Repeat the procedure for the other appendage.

29. Remove the bowl and balls from the work surface.

35. To test the ability to perform a case 4B Grasp, place the bowl, filled with the marbles, on the work surface.

36. Ask the individual to remove one marble from the bowl. Record the result. Ask the individual to put the marble back in the bowl. Record the result.

37. Repeat the procedure for the other appendage.

38. Remove the bowl and marbles from the area.

39. To test the ability to perform a case $4 \mathrm{C}$ Grasp, place the bowl, filled with the b-b's, on the work surface in a location easily accessible to the individual.

40. Ask the individual to remove one $b$-b from the bowl. Record the result. Ask the individual to place the b-b back in the bowl. Record the result. 
41. Repeat the procedure for the other appendage.

42. Remove the bowl and b-b's from the area.

43. To test the ability to perform a case 5 , contact or sliding, Grasp, place the shoe box on the work surface close to the individual.

44. Ask the individual to push the box away from him/herself. Record the result.

45. Repeat the procedure for the other appendage.

46. To test the ability to perform a case 5, hook, Grasp, place the shoe box on the work surface away from the individual, but within a reachable distance.

47. Ask the individual to pull the box toward him/herself. Record the result.

48. Repeat the procedure for the other appendage.

49. Remove the box from the area.

Be sure to make notes of anything that pertains to the individual's performance or behavior. 


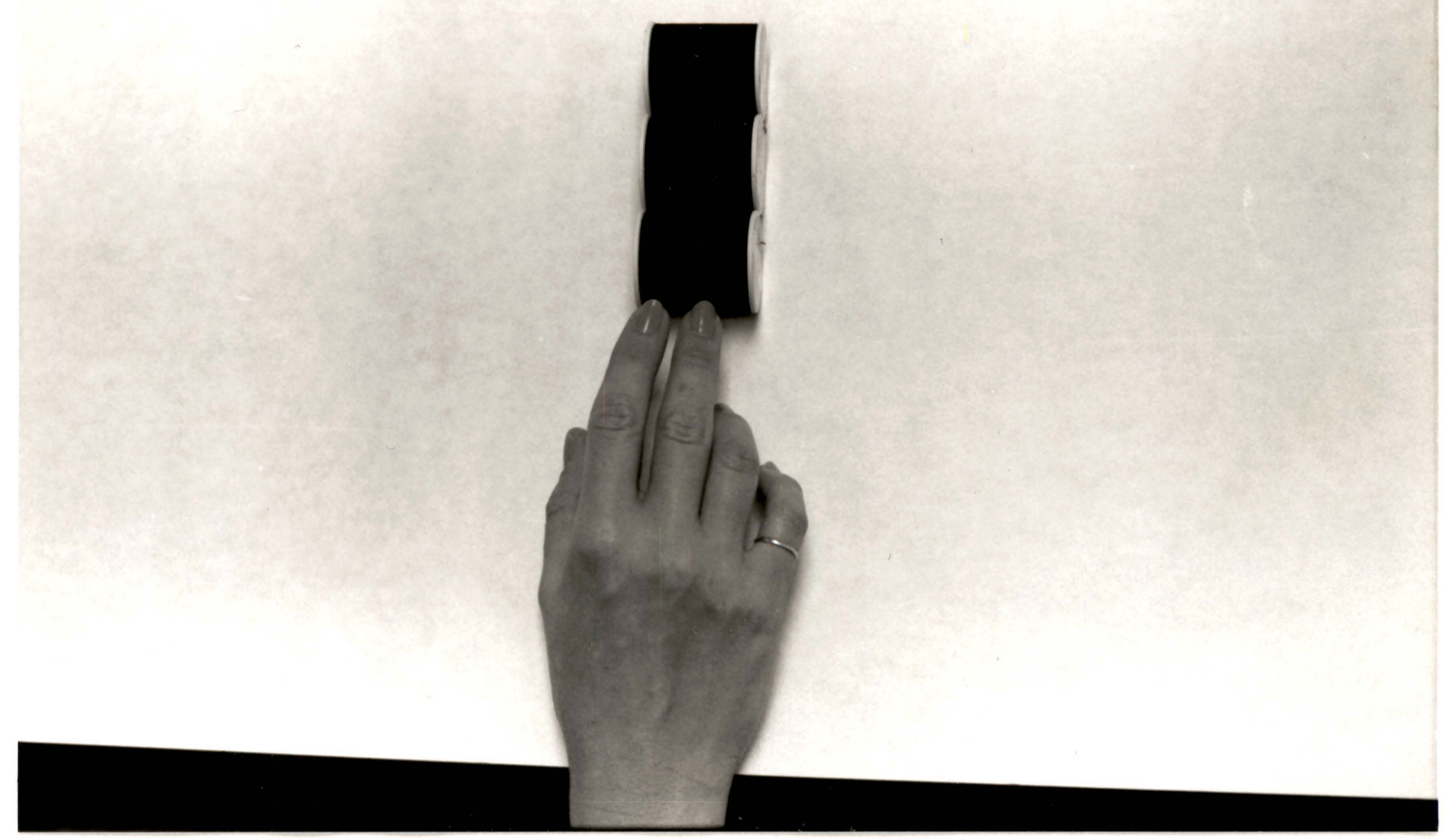

Figure 6. Placement of spools for a case 1C1 Grasp. 


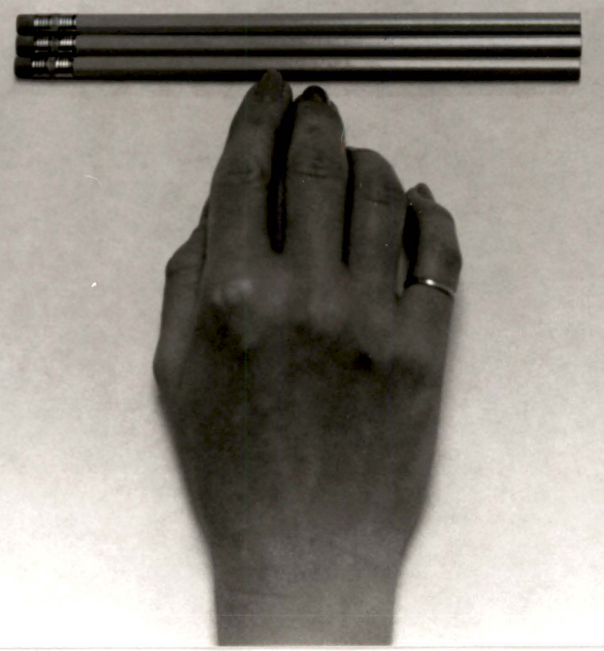

Figure 7. Placement of pencils for a case 1C2 Grasp. 


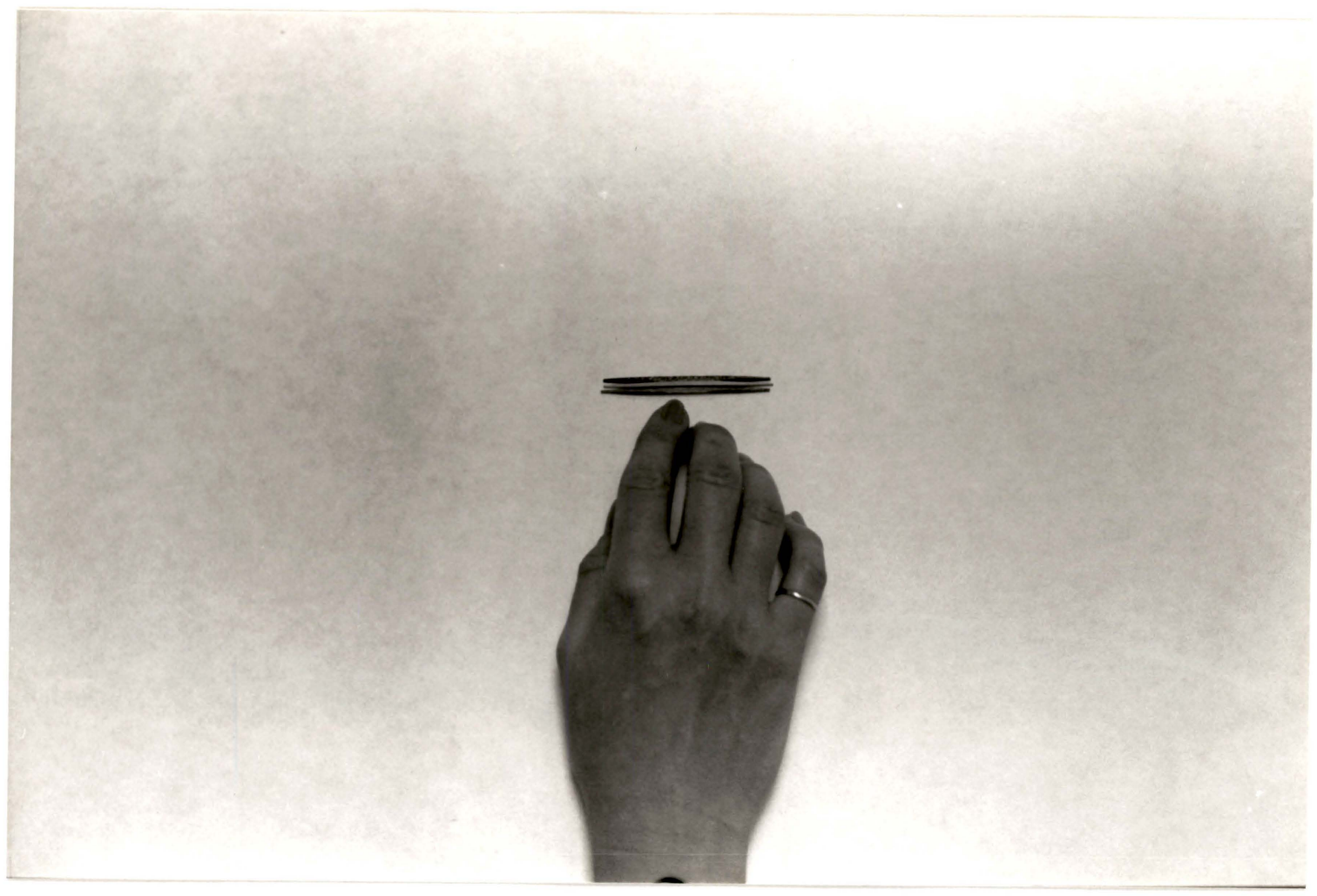

Figure 8. Placement of toothpicks for a case 1 C3 grasp. 


\section{Move}

Move is the basic motion employed when the predominant purpose is to transport an object to a destination.

- The appendage must exert control over the object during the motion.

- The appendage may be pushing the object or sliding it; it is not necessary to carry the object.

Cases of Move

Case A- Move an object to another appendage or against a stop.

Case B- Move an object to an approximate or indefinite location.

Case C- Move an object to an exact location.

\section{Objective for Testing Move}

The objective for testing Move is to determine if the individual can relocate an object which is already under control.

\section{Materials Required to Test Move}

(see Appendix C for specifics)

- horizontal work surface

- a toy block (if Grasp has been tested, use an object which you have already determined the individual can easily control).

- a thick book

- *Move Evaluation form 
*Items provided with the manual.

Procedure for Testing Move

1. Answer questions 1 and 2 on the Move Evaluation form.

2. Position the individual so that the work surface is comfortably accessible by the appendage to be tested.

3. If two appendages will be tested, begin testing with the dominant or preferred appendage. Indicate this by circling the appropriate letter on the first chart; L-left, Ccenter, R-right.

4. To test the ability to perform a case A Move, place the book on the work surface at a location away from the individual, but within the individual's range of reach. The spine of the book should be facing the individual. Place the block at a location where the individual can easily grasp it.

5. Ask the individual to place the block next to the book so that a surface of the block is touching the spine of the book. Record the result by placing the appropriate evaluation code in the corresponding box.

6. Indicate the other appendage to be tested on the second chart. Repeat the procedure for the other appendage.

7. Remove the book from the work surface. 
8. To test the ability to perform a case B Move, place the block on the work surface near the individual.

9. Ask the individual to place the block somewhere on the right half of the work surface, then on the left half. Record the result.

10. Repeat the procedure for the other appendage.

11. To test the ability to perform a case C Move, select an exact location on the work surface. This may be at the center or the side, but within the individual's range of reach. Mark this point with chalk or a piece of masking tape.

12. Ask the individual to place the block on the mark. Record the result.

13. Repeat the procedure for the other appendage.

14. Remove the block and the mark from the work surface. 


\section{Turn}

Turn is the basic motion employed when the predominant purpose is to rotate an object around an axis.

- the axis of rotation may be parallel or perpendicular** to the axis of the appendage.

Objective for Testing Turn

The objective for testing turn is to determine the individual's ability to rotate objects.

Materials Required to Test Turn

(see Appendix C for specifics)

- horizontal work surface

- a jar with a screw-on lid

- door with a rotating door knob

- *Turn Evaluation form

* Items provided with the manual.

Procedure for Testing Turn 
1. Answer questions 1 and 2 on the Turn Evaluation form.

2. Position the individual so that the work surface is easily accessible by the appendage to be tested.

3.If two appendages will be tested, begin by testing the dominant or preferred appendage. Indicate this by circling the appropriate letter on the first chart; L-left, C-center, R-right.

4. To test the ability to perform a Turn with the axis of rotation perpendicular to the axis of the appendage, place the jar on the work surface at a location easily accessible to the individual. The lid should be on the jar, but not too tight.

5. Ask the individual to remove the lid from the jar (this should be a counter-clockwise motion). Record the result by placing the appropriate letter in the corresponding box on the chart.

6. Ask the individual to put the lid back on the jar(this should be a clockwise motion). Record the result.

7. Repeat the procedure for the other appendage. Remove the jar from the work surface.

8. To test the ability to perform a Turn with the axis of rotation parallel to the axis of the appendage, position the individual so that the appendage being tested is on the same plane as the door knob. 
Note:Determine if the individual knows clockwise and counter-clockwise direction. Demonstrate the directions if the individual does not know.

9. Ask the individual to turn the knob in a clockwise direction. Record the result.

10. Ask the individual to turn the knob in a counter-clockwise direction. Record the result.

11. Repeat the procedure for the other appendage.

** It should be noted that this is not considered a Turn by most conventions. However, for ease of classification, and compliance with domestic nomenclature, it is considered a Turn in this context.

Be sure to make notes of anything that pertains to the individual's performance or behavior. 


\section{Position}

Position is the basic motion employed to properly orient an object with another object in a specific place so that further work may be more readily performed.

- An accurate and predetermined relationship between the objects must be attained.

- Normally, only objects can be positioned; occasionally, the appendage may be used as a tool and considered as an object in positioning.

\section{Cases of Position}

Case of Symmetry- The geometric properties of the engaging and engaged parts as they affect the amount of orientation required prior to insertion. (Orientation is the rotating of one part about the common axis of engagement so that it can be mated with the other part). (see figure 9)

Symmetrical- The parts can be engaged in an infinite number of ways about the axis of insertion.

Semi-Symmetrical- The parts can be engaged in two or several ways about the axis of insertion.

Non-Symmetrical- The parts can be engaged in only one way about the axis of insertion.

Objective for Testing Position

The objective for testing Position is to determine if the individual is capable of aligning and orienting objects. 


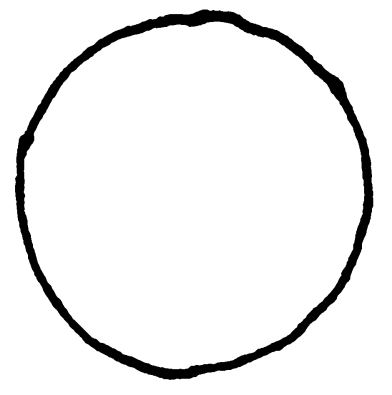

Symmetrical

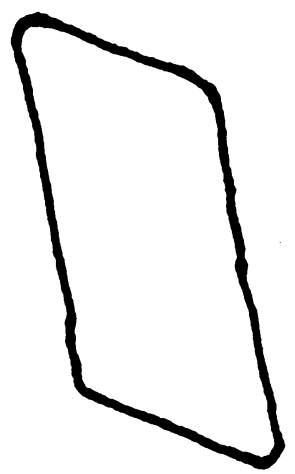

Semi-symmetrical

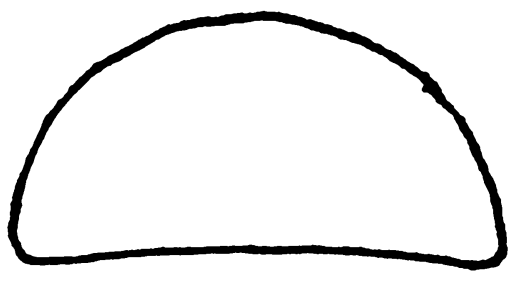

Non-symmetrical

Figure 9. Cases of symmetry. 
Materials Required to Test Position

(see Appendix C for specifics)

- horizontal work surface

- a "Form Fitter" example (see figure 5 in Appendix C).

- *Position Evaluation form

* Items provided with the manual.

Procedure for Testing Position

1. Answer questions 1 and 2 on the Position Evaluation form.

2. Position the individual so that the work surface is comfortably accessible by the appendage to be tested.

3. If two appendages are to be tested, begin with the dominant or preferred appendage. Indicate this on the first chart by circling the appropriate letter; L-left, C-center, R-right.

4. Place the box on the work surface at a location easily accessible to the individual.

5. Select a symmetrical figure. Make sure the corresponding hole in the box is visible to the individual.

6. Place the figure next to the box. Ask the individual to put the figure into the matching hole. Record the result. 
7. Indicate the other appendage on the second chart. Remove the figure and repeat the procedure for the other appendage.

8. Repeat the procedure, beginning at step 4 , for a semi-symmetrical, and nonsymmetrical figure.

9. Remove the objects from the work surface.

Be sure to make note of anything that pertains to the individual's performance or behavior. 


\section{Engage and Disengage}

Engage is the basic motion employed to unite one object with another where there is a force required.

- A force must be present. Merely placing one object with another would not be an engage.

\section{Cases of Engage}

Case 1- Engage requires only slight effort to unite the objects.

Case 2- Engage requires noticeable effort to unite objects.

Case 3- Engage requires considerable effort to unite objects.

Disengage is the basic motion employed to separate one object from another where there is a sudden ending of resistance.

- Friction or recoil must be present.

- There must be a noticeable break in the movement of the appendage.

\section{Cases of Disengage}

Case 1- Disengage requires only a slight effort to break contact and results in separation with minimal recoil that blends smoothly into the subsequent motion.

Case 2- Disengage requires noticeable effort to break contact and is followed by slight recoil denoting separation. 
Case 3- Disengage requires considerable effort to break contact, readily evidenced by marked recoil.

Objective for Testing Engage and Disengage The objective for testing Engage and Disengage is to determine the individual's ability to unite and separate different objects where various levels of effort are required.

Materials Required to Test Engage and Disengage

(see Appendix C for specifics)

- horizontal work surface

- a piece of construction paper

- a large paper clip

- ink pen with "snap- on" cap

- 3-pin electrical adaptor

- 3-pin electrical plug (see figure 6 in Appendix C).

- *Engage/Disengage Evaluation form

* Items provided with the manual.

Procedure for Testing Engage and Disengage

1. Answer questions 1 and 2 on the Engage/Disengage Evaluation form.

2. Position the individual so that the work surface is comfortably accessible by the appendage to be tested. 
3. To test the ability to perform a case 1 Engage, place the paper and the paper clip on the work surface.

4. Ask the individual to slide the paper clip onto the piece of paper. Record the result. If the individual was unable to do this, do so yourself at this time.

5. To test the ability to perform a case 1 Disengage, ask the individual to slide the paper clip off the paper. Record the result.

6. Remove the paper and paper clip from the work surface.

7. To test a case 2 Engage, place the pen and cap on the work surface at a location easily accessible to the individual.

8. Ask the individual to place the cap on the pen so that it "snaps" on completely. Record the result. If the individual was unable to place the cap on the pen, do so yourself at this time.

9. To test the ability to perform a case 2 Disengage, ask the individual to remove the cap from the pen. Record the result.

10. Remove the cap and pen from the work surface.

11. To test the ability to perform a case 3 Engage, place the plug and adaptor on the work surface at a location easily accessible to the individual. 
12. Ask the individual to insert the plug completely into the adaptor. Record the result. If the individual is unable to insert the plug, do so yourself at this time.

13. To test the ability to perform a case 3 Disengage, ask the individual to remove the plug from the adaptor. Record the result.

14. Remove the plug and adaptor from the work surface.

Be sure to make notes of anything that pertains to the individual's performance or behavior. 


\section{THE POST-ASSESSMENT PHASE}

\section{Interpreting and Applying the Results}

After all the tests have been administered, you will have a collection of forms completed with the evaluation of the individual's performance of the motion descriptors. When these evaluation forms are compiled their result is a profile of the individual's manipulation capability. How this profile is utilized will vary depending on the needs and desires of the individual. Some suggestions for interpreting and applying the results are given here, but there are many more possibilities.

In order to interpret the results, the person viewing the profile must be familiar with the motion descriptors. You should already be familiar with them from administering the assessment. Other people who may want to use the profile are engineers, employers, physical therapists, and teachers. Some of these people may already be familiar with fundamental motions. If they are not, the motions can easily be learned from the definitions presented earlier in the manual.

Once the motion descriptors are understood, interpreting the results is fairly simple. The interpretation is basically a comparison of the recorded performance and the evaluation code. In the case where the motion was executed completely, the interpretation is clear, and straight forward. In the other cases, the notes taken during the assessment become important. If an individual was unable to execute a motion, it may be helpful and informative to know the reason or problem which prevented the execution.

The applications of the results can take many forms. One means of applying the results is as an aid to securing employment for the individual. An existing or perspective 
job must first be broken down into the fundamental motions required in its performance. This is a type of job profile. This profile can then be compared to the individual's profile. If the comparison shows the individual is capable of performing all the required motions, then he/she is a likely candidate for the job.

Another means of applying the results is to aid in the design of an adaptive device for daily living or employment. The first step would again be to break the task into fundamental motions. The profiles can then be compared to determine the point where the individual has a problem performing the task. This is the focus on which an adaptive device can be designed. The device can utilize the individuals 's abilities to complete the task where the individual alone cannot.

An opposite approach to this would be to modify the task so that it requires only the motions the individual is capable of performing. The cases where all these means can be applied are numerous. However the results are applied, it can lead to an easier and more fulfilling life for the individual. 
APPENDIX A

PRE-ASSESSMENT INFORMATION QUESTIONNAIRES 


\section{Pre-Assessment Information (Part I)}

This questionnaire is designed to aid in determining the appropriate method of assessment for the individual to be assessed. The questions should be answered by the individual or a family member, aide/attendant, physician, or other responsible person.

* In this and subsequent questionnaires, information, and guidelines, the term "appendage" will refer to an arm, hand, leg, foot, headstick, mouthstick, or any extension of the body which is used for manipulation.

Please answer the questions by making an " $\mathrm{X}$ " in the applicable blank.

1. The individual's condition is:

stable

deteriorating

2. Disability classification:

Cerebral Palsy

Head Trauma

Muscular Dystrophy Multiple Sclerosis

Spinal Cord Injury Cardio Vascular

Post Polio Other (explain)

3. Other impairments:

Sight Communicative Disorder

Hearing 
4. Are there any medical restrictions?

No

Yes ,explain

5. Is the individual on any medication?

No Yes name and dose

6. The individual is:

Ambulatory Wheel chair bound

7. Does the individual have a consistent yes/no response (does not necessarily have to be verbal)?

Yes No

8. Is some manual manipulation capability present?

Yes No

9. Is the individual able to move one or both arms, or other appendage used for manipulation, independently in horizontal and vertical directions?

Yes

No

10. Does the individual possess sufficient ability to understand and follow verbal or gestural instructions?

Yes No 
11. Add any information about the individual which may affect the administration or outcome of an assessment. 


\section{Pre-Assessment Information (Part II)}

Based on observation or experience, does the individual exhibit the basic capability to:

1. Reach for a pair of pliers resting some place on a work table.

Yes No

2. Reach for a screw jumbled in a pile with other screws.

Yes No

3. Hold a deck of cards with one appendage and then transfer it to another.

Yes No

4. Move a pencil to another place on a desk to make room for work papers.

Yes No

5. Align the point of a screwdriver to the slotted head of a screw.

Yes No

6. Turn a screwdriver to drive a screw into a hole.

Yes No 
7. Pick up a washer which is lying flat on a table.

Yes No

8. Pick up one pencil from a row of pencils lying on a table.

Yes No

9.Shift a pencil that is being used to write in order to use the eraser at the other end. Yes No

10. Pick up a marble jumbled with other marbles.

Yes No

11. Remove the cap from an ink pen.

Yes No

12.Place the cap on an ink pen.

Yes No

13.Position a square peg in a square hole.

Yes No 
APPENDIX B

EVALUATION FORMS 


\section{Reach Evaluation}

1. What appendage will be used to perform the Reach motion?

2. Location and type of work surface used?

3. Will one or two appendages be tested?

Evaluation Code for Reach

$\mathrm{X}$ - Reach was executed completely, a conscious, intentional, and repeatable motion

A- Reach was 'accidental', the result of a spastic or uncontrolled motion

O- Reach was attempted, but not completed

- Leave box blank if Reach was not attempted 
Bange of Horizental Reach Chart

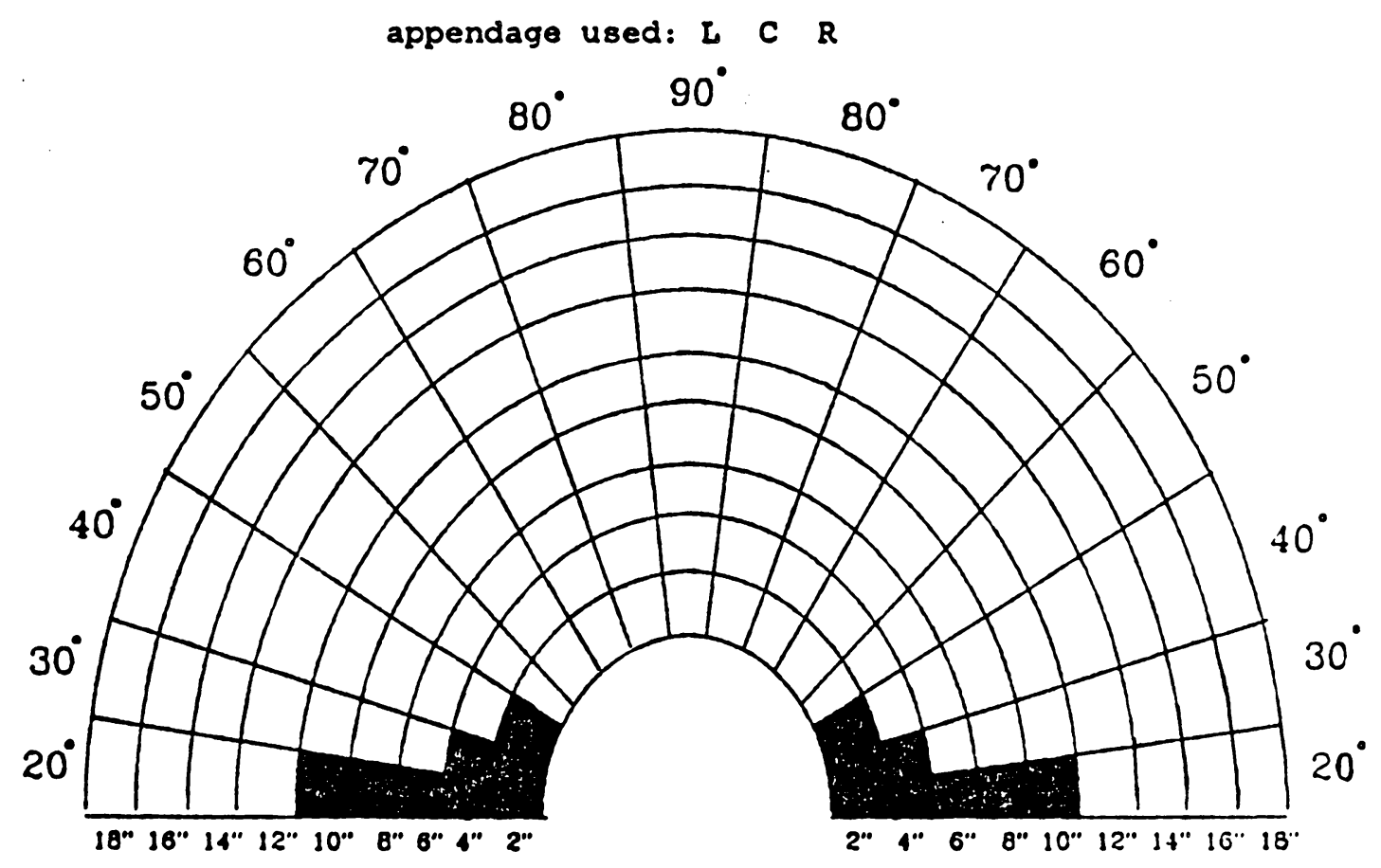

Bange of Herizontal Reach Chart

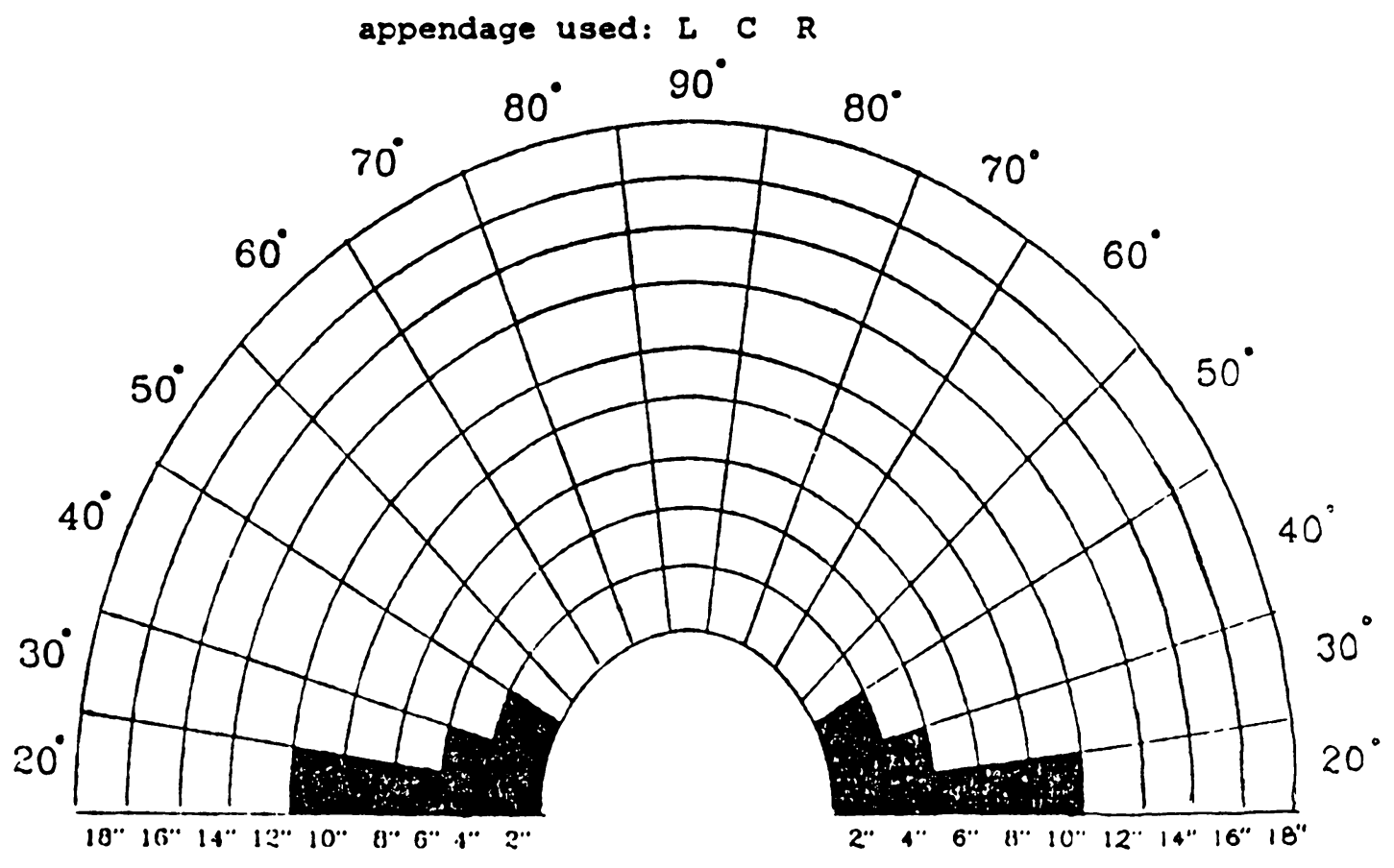




\section{NOTES}




\section{Vertical Reach Chart}

appendage used: L C R

\begin{tabular}{|c|c|}
\hline Position(inches/degrees) & Height(inches) \\
\hline & \\
\hline & \\
\hline & \\
\hline & \\
\hline & \\
\hline & \\
\hline & \\
\hline & \\
\hline & \\
\hline & \\
\hline & \\
\hline & \\
\hline
\end{tabular}




\section{Vertical Reach Chart}

appendage used: L C R

\begin{tabular}{|c|c|}
\hline Position(inches/degrees) & Height(inches) \\
\hline & \\
\hline & \\
\hline & \\
\hline & \\
\hline & \\
\hline & \\
\hline & \\
\hline & \\
\hline & \\
\hline & \\
\hline & \\
\hline & \\
\hline
\end{tabular}

NOTES 


\section{Grasp and Release Evaluation}

1. What appendage will be used to perform the Grasp motion?

2. Will one or two appendages be tested?

Evaluation Code for Grasp

X- Grasp was executed completely, a conscious, intentional, and repeatable motion

A- Grasp was 'accidental', the result of spastic or uncontrolled motion

O- Grasp was attempted, but not completed

- Leave box blank if Grasp was not attempted

Evaluation Code for Release

$\mathrm{X}$ - Release was executed completely, a conscious, intentional, and repeatable motion

A- Release was 'accidental', the result of spastic or uncontrolled motion

O- Release was not executed

-Leave box blank if Release was not attempted 
Grasp Chart

appendage used: L C R

\begin{tabular}{|c|c|c|}
\hline Case & Grasp & Release \\
\hline $1 \mathrm{~A}$ & & \\
\hline 1B & & \\
\hline $\mathrm{CCl}$ & & \\
\hline 1C2 & & \\
\hline $1 \mathrm{C} 3$ & & \\
\hline 2 & & \\
\hline 3 & & \\
\hline $4 \mathrm{~A}$ & & \\
\hline $4 B$ & & \\
\hline $4 \mathrm{C}$ & & \\
\hline 5 & & \\
\hline
\end{tabular}

NOTES 
Grasp Chart

appendage used: $\mathrm{L} \quad \mathrm{C} \quad \mathrm{R}$

\begin{tabular}{|c|c|c|}
\hline Case & Grasp & Release \\
\hline $1 \mathrm{~A}$ & & \\
\hline 1B & & \\
\hline $\mathrm{CCl}$ & & \\
\hline $1 \mathrm{C} 2$ & & \\
\hline $1 \mathrm{C} 3$ & & \\
\hline 2 & & \\
\hline 3 & & \\
\hline $4 \mathrm{~A}$ & & \\
\hline $4 B$ & & \\
\hline $4 C$ & & \\
\hline 5 & & \\
\hline
\end{tabular}

NOTES 


\section{Move Evaluation}

1. What appendage will be used to perform the Move motion?

2. Will one or two appendages be tested?

Evaluation Code for Move

$\mathrm{X}$ - Move was executed completely, a conscious, intentional, and repeatable motion

A- Move was 'accidental' the result of spastic or uncontrolled motion

O- Move was attempted, but not completed

- Leave box blank if Move was not attempted 


\section{Move Chart}

appendage used: $\mathrm{L}$ C R

Case A
Case B
Case C

Move Chart

appendage used: $\mathrm{L} \quad \mathrm{C} \quad \mathrm{R}$

\begin{tabular}{|c|c|}
\hline Case A & \\
\hline Case B & \\
\hline Case C & \\
\hline
\end{tabular}




\section{NOTES}




\section{Turn Evaluation}

1. What appendage will be used to perform the Turn motion?

2. Will one or two appendages be tested?

Evaluation Code for Turn

$\mathrm{X}$ - Turn was executed completely, a conscious, intentional, and repeatable motion

A- Turn was 'accidental', the result of spastic or uncontrolled motion

O- Turn was attempted, but not completed

- Leave box blank if Turn was not attempted 


\section{Turn Chart}

appendage used: $\mathrm{L} C \mathrm{R}$
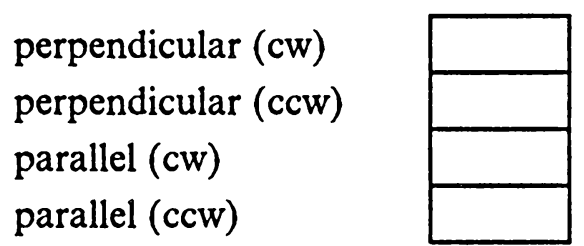

\section{Turn Chart}

appendage used: $\mathrm{L} \quad \mathrm{C} \quad \mathrm{R}$
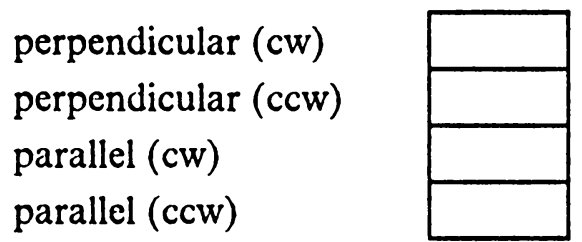
NOTES 


\section{Position Evaluation}

1. What appendage will be used to perform the Position motion?

2. Will one or two appendages be tested?

Evaluation Code for Position

$\mathrm{X}$ - Position was executed completely, a conscious, intentional, and repeatable motion

A- Position was 'accidental', the result of spastic or uncontrolled motion

O- Position was attempted, but alignment and orientation were not achieved

- Leave box blank if Position was not attempted 
Position Chart

appendage used: $\mathrm{L} \quad \mathrm{C} R$

symmetrical

semi-symmetrical

non-symmetrical

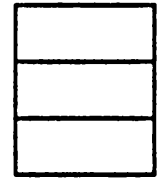

Position Chart

appendage used: $L \quad C \quad R$

symmetrical

semi-symmetrical

non-symmetrical

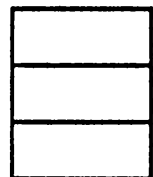


NOTES

APPENDIX 1A 


\section{Engage/Disengage Evaluation}

1. What appendage will be used to perform the engage/disengage motion?

2. Will one or two appendages be tested?

If only one appendage will be used, indicate which

Evaluation Code for Engage/Disengage

$\mathrm{X}$ - Engage or Disengage was executed completely, a conscious, intentional, and repeatable motion

S- Engage was started, objects were properly aligned and oriented, but individual lacked the strength to complete the motion

S- Disengage was not completed due to lack of strength

O- Engage was attempted, but alignment and orientation were not achieved

O- Disengage was attempted, but not completed due to lack of control of the objects

- Leave box blank if engage or disengage were not attempted. 
Engage/Disengage Chart

\begin{tabular}{l|l|l|}
\multicolumn{1}{c}{} & \multicolumn{1}{c}{ Engage } & \multicolumn{1}{c}{ Disengage } \\
\cline { 3 - 4 } Case 1 & & \\
\cline { 2 - 3 } Case 2 & & \\
\cline { 3 - 4 } Case 3 & & \\
\cline { 2 - 3 } & &
\end{tabular}

NOTES 
APPENDIX C

\section{REQUIRED MATERIALS}


The following materials are those needed to administer an assessment, and which are not included with the manual. See the General Guidelines on Assessment and the Assessment Bases and Procedures for further instructions on the materials to use.

- a horizontal work surface, at least $58^{\prime \prime} \times 20^{\prime \prime}$

- a yardstick

- a toy wooden block, 1 1/4" sides

- a washer, $3 / 4^{\prime \prime}$ diameter, $1 / 8^{\prime \prime}$ thick

- three spools of thread, $11 / 2^{\prime \prime}$ diameter

- three pencils, no. 2 wooden

- three cylindrical wooden toothpicks

- six standard table tennis balls

- a 2 cup bowl

- twelve glass marbles 5/8" diameter

- one $60 z$ custard cup

- twelve b-b's, $4.5 \mathrm{~mm}$

- a shoe box

- a dictionary or other thick book

- a jar with a screw-on lid, 2-2 1/2" diameter lids

- a door with a rotating door knob

- a piece of medium weight construction paper

- a large paper clip

- an ink pen with a "snap-on" cap

- a children's toy where figures of different shapes are placed in different shaped holes, the Play Skool "Form Fitter" is one 
- a 3-pin electrical adaptor

- a 3-pin electrical plug 


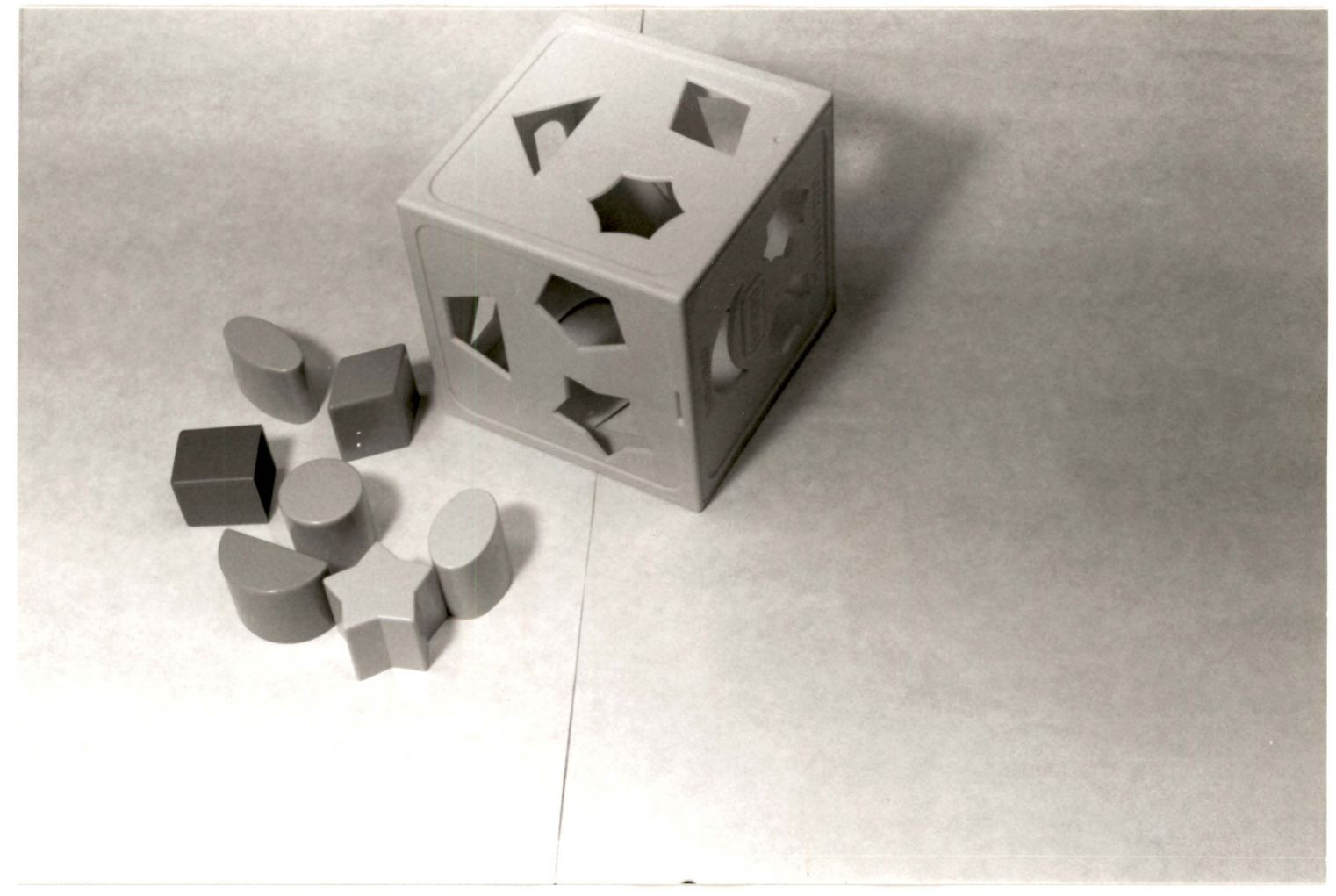

Figure 10. "Form Fitter" children's toy. 


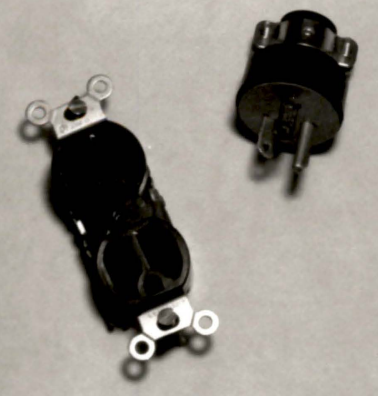

Figure 11. 3-pin electrical adaptor and 3-pin electrical plug. 
The vita has been removed from the scanned document 